\title{
Sleep Patterns and Associated Factors in Children and Adolescents with Inflammatory Bowel Disease
}

\author{
Margo M. Szabo
}

Follow this and additional works at: https://researchrepository.wvu.edu/etd

\section{Recommended Citation}

Szabo, Margo M., "Sleep Patterns and Associated Factors in Children and Adolescents with Inflammatory Bowel Disease" (2016). Graduate Theses, Dissertations, and Problem Reports. 6760.

https://researchrepository.wvu.edu/etd/6760

This Dissertation is protected by copyright and/or related rights. It has been brought to you by the The Research Repository @ WVU with permission from the rights-holder(s). You are free to use this Dissertation in any way that is permitted by the copyright and related rights legislation that applies to your use. For other uses you must obtain permission from the rights-holder(s) directly, unless additional rights are indicated by a Creative Commons license in the record and/ or on the work itself. This Dissertation has been accepted for inclusion in WVU Graduate Theses, Dissertations, and Problem Reports collection by an authorized administrator of The Research Repository @ WVU.

For more information, please contact researchrepository@mail.wvu.edu. 
Sleep Patterns and Associated Factors in Children and Adolescents with Inflammatory Bowel Disease

Margo M. Szabo, M.S.

Dissertation submitted

to The Eberly College of Arts and Sciences

at West Virginia University

in partial fulfillment of the requirements

for the degree of

Doctor of Philosophy

in

Psychology

Christina L. Duncan, Ph.D., Chair

Amy Fiske, Ph.D.

Cheryl B. McNeil, Ph.D.

Hawley E. Montgomery-Downs, Ph.D.

Amy K. Root, Ph.D.

Department of Psychology

Morgantown, West Virginia

2016

Keywords: children, adolescents, inflammatory bowel disease, sleep

Copyright 2016 Margo M. Szabo 


\begin{abstract}
Sleep Patterns and Associated Factors in Children and Adolescents with

Inflammatory Bowel Disease
\end{abstract}

Margo M. Szabo, M.S.

Youth with inflammatory bowel disease (IBD) may be at increased risk for sleep difficulties due to the inflammatory nature of their disease. Moreover, previous research has demonstrated that children and adolescents with IBD experience impairment across a variety of psychosocial domains. However, the current literature has yet to examine the complex interplay between sleep, disease-related symptoms, and psychosocial factors such as mood and health-related quality of life in youth with both types of IBD (i.e., Crohn's disease and ulcerative colitis). Therefore, the purpose of this study was to examine sleep patterns and associated factors, including pain, disease activity, mood, and health-related quality of life, in children and adolescents with Crohn's disease or ulcerative colitis. A sample of 25 children and adolescents with IBD (Mage $=14.25$; range $=10$ 18 years; $56 \%$ male) and their caregivers were recruited from a pediatric gastroenterology clinic in West Virginia. Results indicated no significant association for sleep with abdominal pain, negative affect, or positive affect. However, significant associations were revealed among sleep and patient age, disease activity, and health-related quality of life. Youth with IBD also demonstrated greater sleep disturbance than previously published data using normatively developing samples. Findings of the current study suggest that children and adolescents with IBD experience significant sleep disturbance, which may impact their disease activity and psychosocial functioning. Consequently, healthcare providers should screen for and address sleep difficulties to optimize better outcomes in their pediatric patients. 


\section{ACKNOWLEDGEMENTS}

I would like to thank my mentor, Christina Duncan, for her persistence in helping me to create a project that was consistent with my interests and professional goals. Her encouragement and support over the past five years has been extraordinary, and her humor has made the seemingly daunting process of graduate school enjoyable. I am grateful to Hawley Montgomery-Downs for sharing her expertise in pediatric sleep research and allowing me to borrow her actigraphy equipment, which was invaluable to the execution of this project. I also appreciate the thoughtful comments of my other committee members (Cheryl McNeil, Amy Fiske, and Amy Root) that helped shape this project. I also would like to thank Brian Riedel and Audra Rouster for their assistance in recruiting participants and helping me to better understand the nuances of working with pediatric inflammatory bowel disease. I want to acknowledge the all of the members of the WVU Pediatric Psychology lab for their help with recruitment, data entry, and support throughout this process. In particular, Ellen Manegold's reliability and persistence with data collection and management while I was on internship were integral to this project's success. I am so grateful to all the families who took the time to participate and make this project possible. Finally, I would like to thank my family and my husband for their unconditional love and support throughout my educational and professional endeavors. 


\section{TABLE OF CONTENTS}

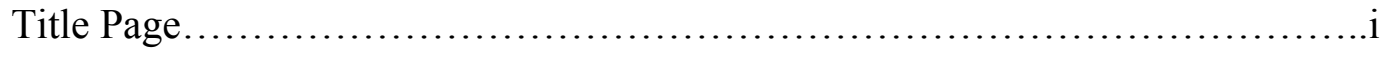

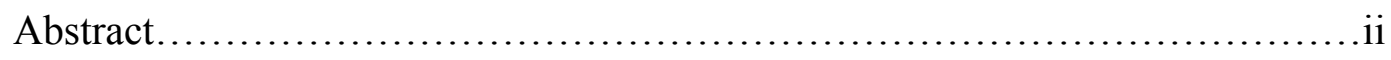

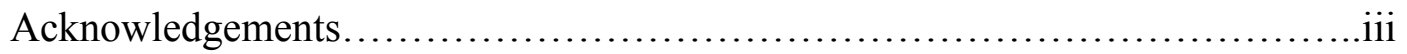

Table of Contents ...........................................................

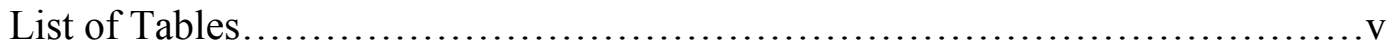

Introduction and Literature Review...........................................

Summary \& Rationale..................................................13

Specific Aims......................................................... 16

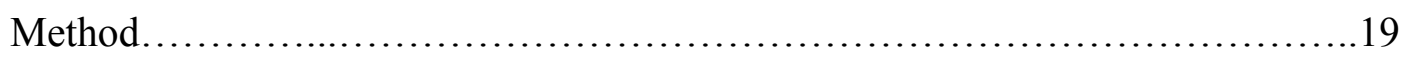

Participants............................................................ 19

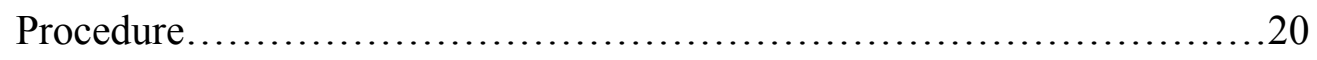

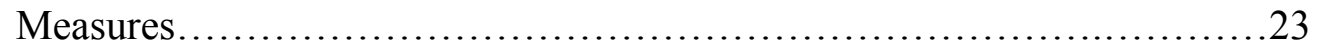

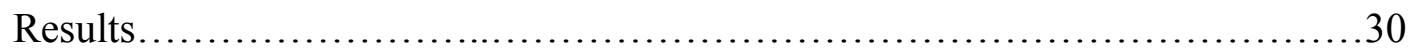

Power Analysis......................................................... 30

Preliminary Analysis................................................. 30

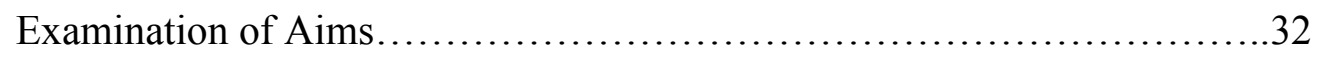

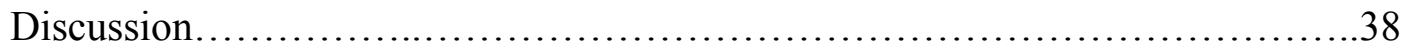

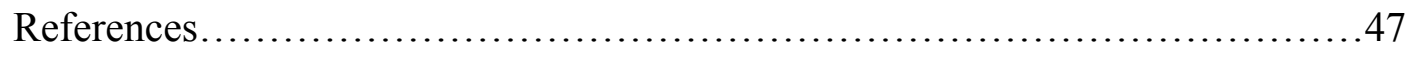

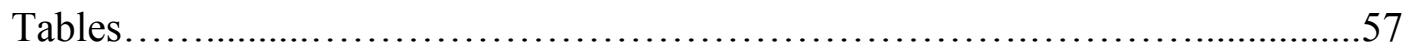




\section{LIST OF TABLES}

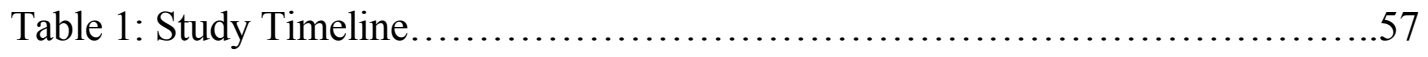

Table 2: Schedule of Participant Remuneration..................................58

Table 3: Sample Demographics.........................................59-60

Table 4: Descriptives of Study Variables..................................61-62

Table 5: Descriptives of Parental Beliefs and Knowledge Questions.................63-64

Table 6: Sleep Variables compared to Healthy Samples..........................65

Table 7: Correlations among Subjective Sleep Variables, Disease Activity, HRQOL,

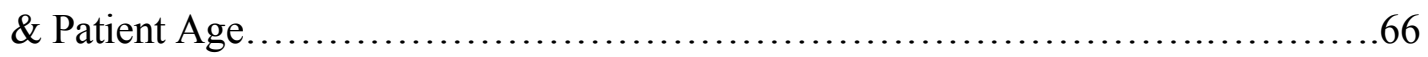

Table 8: Correlations among Objective Sleep Variables, Disease Activity, HRQOL,

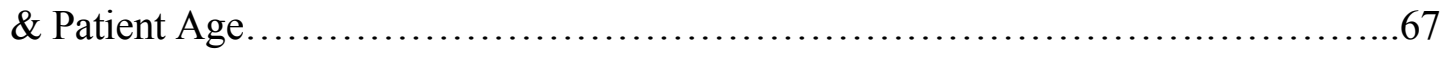

Table 9: Multilevel Models of Abdominal Pain Predicting Sleep Variables...........68-69

Table 10: Multilevel Model of Sleep Variables Predicting Abdominal Pain............70

Table 11: Multilevel Models of Negative Affect Predicting Sleep Variables...........71-72

Table 12: Multilevel Model of Sleep Variables Predicting Negative Affect............73

Table 13: Multilevel Models of Positive Affect Predicting Sleep Variables.............74-75

Table 14: Multilevel Model of Sleep Variables Predicting Positive Affect.............76 
Sleep Patterns and Associated Factors in Children and Adolescents with Inflammatory Bowel Disease

Inflammatory Bowel Disease (IBD) is a group of chronic medical conditions that are characterized by an abnormal immune response and gastrointestinal inflammation (Centers for Disease Control and Prevention [CDC], 2014). In addition, IBD is marked by periods of disease activity (i.e., symptom flare-ups) and remission, which are unpredictable in nature (Banez, \& Cunningham, 2009). The CDC (2014) currently estimates that 1.4 million individuals in the United States are living with IBD, of which approximately $10 \%$ are children under the age of 18 . IBD is more common in Caucasian individuals than other ethnic groups and is equally prevalent in males and females (Crohn's \& Colitis Foundation of America [CCFA], 2014). A recent review indicated a global trend towards increasing incidence of IBD among children and adolescents (Benchimol et al., 2011). Although the specific cause of IBD is currently unknown, research suggests genetic factors and immune response to environmental triggers may be involved in the etiology of IBD (Kim \& Ferry, 2004).

Individuals with IBD are diagnosed with one of two disorders, Crohn's disease (CD) or ulcerative colitis (UC). Symptoms of both disorders are separated into three categories including gastrointestinal (e.g., diarrhea, abdominal cramping and pain, rectal bleeding, and constipation), systematic (e.g., growth failure, weight loss, fever), and endocrine (e.g., delayed puberty, osteoporosis) (Kim \& Ferry, 2004). Despite the similar symptoms associated with intestinal inflammation, there are aspects that differentiate $\mathrm{UC}$ and $\mathrm{CD}$. In UC, inflammation is restricted to the colon and the top layers of the bowel, while inflammation may occur at part of the gastrointestinal tract from the mouth to the anus and may impact all layers of the bowel in CD (CDC, 2014). 
Given the similarity in symptomatology and underlying issue of intestinal inflammation, $\mathrm{UC}$ and $\mathrm{CD}$ have similar treatment regimens. Medications designed to reduce inflammation and frequency of symptom flare-ups in UC and CD include aminosalicylates, immunomodulators, corticosteroids, anti-tumor necrosis factor (TNF) agents, and antibiotics (CDC, 2014). The CCFA (2014) currently recommends aminosalicylates to treat mild to moderate disease, corticosteroids and anti-TNF agents to treat moderate to severe disease, and immunomodulators to be used for individuals that have not had success with other medications. However, corticosteroids are not recommended as long-term maintenance medication for IBD given their side effects (e.g., weight gain, osteoporosis, sleep disturbance) (Buchman, 2001). In addition, antibiotics can be used to treat infections (CCFA, 2014). Given the nutritional issues present in IBD, patients must maintain a healthy, well-balanced diet in which they avoid foods that trigger gastrointestinal symptoms (e.g., high-fiber and spicy foods) and may require enteral therapy if they experience chronic malnutrition (CCFA, 2014; Kim \& Ferry, 2004). Finally, patients with IBD may require surgery if medications do not successfully treat symptoms or if complications, such as intestinal blockages, occur (CDC, 2014). Although surgery cures UC by removing the entire colon, patients must have additional procedures done to create either external or internal pouches to empty waste materials into (CCFA, 2014). In terms of CD, surgery involves the removal of a portion of the bowel, but does not cure the disease (CCFA, 2014). Thus, patients with CD often have disease recurrences after surgery.

The increasing incidence and issues unique to pediatric IBD, such as embarrassment and intrusiveness of intestinal symptoms (Banez, \& Cunningham, 2009), have generated interest in the psychosocial functioning of these youth. Therefore, several studies have examined various aspects of psychosocial functioning, including rates of depression and anxiety, school and social functioning, family functioning, and health-related quality of life (Greenley et al., 2010; Mackner 
et al., 2013). However, few studies have addressed sleep problems in this population, despite reports implicating circadian rhythm in gastrointestinal diseases (Hoogerwerf, 2009). Moreover, those studies that have assessed sleep problems in pediatric IBD have not examined associations between sleep and the aforementioned psychosocial factors.

\section{Sleep}

Sleep has been implicated in various areas of physical health, including growth and development, immune functioning, and endocrine function (Bryant, Trinder, \& Curtis, 2004; Meltzer \& Mindell, 2009). Although sleep is vital to health, sleep problems are common among children with chronic medical conditions (Palermo \& Owens, 2008). Specifically, research has demonstrated that children with chronic illnesses may experience frequent night awakenings, problems falling asleep, poor sleep quality, decreased sleep duration, disrupted sleep architecture, and other sleep disturbances, including sleep-disordered breathing (Lewandowski, Ward, \& Palermo, 2011). Moreover, disturbed sleep can be associated with a host of daytime sequelae, including fatigue and sleepiness, impaired cognitive and academic functioning, and poor socioemotional functioning (Fallone, Owens, \& Deane, 2002; Meltzer \& Mindell, 2009; Wolfson \& Carskadon, 2003). Because children with chronic illness are already at risk for some of the aforementioned problems such as psychosocial distress (Barlow \& Ellard, 2006), it is essential to examine sleep disturbances within this population.

Despite the increasing interest in examining sleep disturbances in chronic medical conditions, little research has examined this topic in pediatric IBD. However, recent reports have suggested sleep and circadian rhythms may influence the gastrointestinal system (Swanson, Burgess, \& Keskavazian, 2011). More specifically, Swanson and colleagues explained that sleep disruption may affect immune functioning, leading to release of inflammatory proteins (e.g., 
$\mathrm{TNF}-\alpha$ ) and potentially impacting inflammation of the gastrointestinal tract. In turn, inflammatory responses have been linked to disturbed sleep among a number of chronic inflammatory conditions, such as IBD (Ranjbaran et al., 2007b). Given that IBD is characterized by chronic gastrointestinal inflammation and inflammation disrupts sleep, a vicious cycle may occur in which patients with IBD have sleep problems and those sleep problems create additional inflammation (Swanson et al., 2011).

Recognizing the importance of studying sleep in IBD, studies using adult samples have begun to emerge. These studies indicated that adults with IBD report poor sleep quality (Keefer et al., 2006; Ranjbaran et al., 2007a; Zimmerman, 2003), have reduced sleep efficiency (Burgess et al., 2010), and have problems with obstructive sleep apnea (Keefer et al., 2006). Moreover, other studies have demonstrated a relation between increased disease activity and sleep disturbances in adults with IBD (Ali et al., 2013; Ananthakrishnan et al., 2013; Graff et al., 2011). Finally, adultbased IBD research has linked sleep disruptions to increased fatigue (Graff et al., 2013) and decreased quality of life (Keefer et al., 2006; Ranjbaran et al., 2007a). These studies indicate that sleep problems and associated daytime sequelae are common among adults with IBD, which emphasizes the importance of continued research in this area.

Although several studies have examined disordered sleep in adults with IBD, relatively little research has been conducted in pediatric IBD samples. In the first study to investigate this topic, Nachimas and colleagues (2006) administered the Mini-Sleep Questionnaire to 41 Israeli children and adolescents with IBD (mean age $=16.9$ years). Over half the sample $(54 \%)$ reported having moderate or severe sleep disturbance, including daytime fatigue and night awakenings. However, the authors found no association between sleep problems and medical characteristics (e.g., disease activity, medications) in their sample. In addition, sleep disruptions and daytime 
sleepiness were examined among a sample of 161 adolescents aged 10 to 18 years with IBD in comparison to age- and gender-matched healthy peers in Finland (Pirinen et al., 2010). The results revealed greater parent-reported problems with sleeping, nightmares, and daytime tiredness for adolescents with IBD compared to healthy adolescents. Interestingly, the adolescents did not endorse more sleep difficulties than their peers. In contrast, the authors reported an association between IBD symptom severity and sleep, such that adolescents with more severe IBD reported more sleep disturbance than those with mild IBD. However, the authors noted that they did not assess patient use of corticosteroids, which has been shown to disrupt sleep (Huscher et al., 2009), and thus they are unable to determine the mechanism underlying the sleep disturbance.

Most recently, a study assessed the relations among sleep, psychological functioning, pain, and inflammation in youth (ages 9 to 17) with depression and CD (Benhayon et al., 2013). In contrast to Pirinen and colleagues' (2010) findings, Benhayon and colleagues (2013) determined that adolescents with IBD reported more sleep difficulties than healthy adolescents. Greater subjective sleep disturbance among youth with IBD also was associated with increased self-report depression, anxiety, abdominal pain, as well as more severe physician-reported disease (i.e., Pediatric Crohn's Disease Activity Index), but not inflammation, as assessed by blood assays. Moreover, qualitative sleep indicators (e.g., sleep quality, daytime sleepiness) were associated with anxiety, pain, and disease activity, while quantitative sleep indicators (e.g., sleep duration) were only associated with disease activity. However, because all variables, except disease activity, were assessed via self- or parent-report questionnaires, the association may have been due to the shared method variance rather than a true relation between the variables.

The results of the aforementioned studies suggest that youth with IBD may be at risk for sleep disturbance and thus, it may be important to target sleep problems in future interventions 
within this population. However, all previous studies of pediatric samples have utilized self- or parent-reported sleep assessments, which may be inaccurate estimates of sleep patterns due to social desirability or other biases. Moreover, if participants are poor historians, the use of retrospective questionnaires may not provide accurate data regarding sleep. Therefore, future research utilizing objective measures, such as polysomnography (PSG) and actigraphy, may provide more valid assessments of sleep patterns and disturbances. Although PSG is described as the "gold standard" for assessing sleep and diagnosing sleep disorders (Meltzer \& Mindell, 2009), it involves participants staying overnight in sleep laboratory and is both expensive and timeintensive. In contrast, actigraphy, wrist watch-like devices that assess movement, is a less expensive and intensive method of examining sleep patterns (Meltzer, Montgomery-Downs, Insana \& Walsh, 2012). As a result, actigraphy allows researchers to more practically evaluate sleep patterns over time. Overall, research examining of sleep among youth with IBD is in its infancy and it is clear much additional research is needed to describe sleep/wake patterns in this population and investigate factors associated with these patterns.

\section{Pain}

One common symptom of IBD is abdominal pain. Individuals with IBD may experience abdominal pain during symptom flares as a result of intestinal inflammation or obstruction (Bielefeldt, Davis, \& Binion, 2009). Although most patients' pain is relieved during periods of disease quiescence, some individuals continue to experience some degree of pain despite having no indication of obstruction or inflammation (Bielefeldt, Davis, \& Binion, 2009). Thus, abdominal pain may be considered a more chronic or continuous, rather than recurrent, symptom for some patients with IBD and should be monitored during periods of disease activity and remission. Moreover, it is important to investigate how and to what extent abdominal pain affects 
functioning among individuals with IBD. Specifically, examining the association between pain and sleep patterns is critical as previous research has demonstrated that disrupted sleep can influence pain perception and ability to effectively cope with pain in children (Lewin \& Dahl, 1999).

Currently, little research specifically has assessed the impact of abdominal pain on sleep patterns in patients with IBD. Most studies assessing the association between physical symptoms of IBD and sleep have focused on general measures of disease activity (Ali et al., 2013; Ananthakrishnan et al., 2013; Graff et al., 2011; Nachimas et al., 2006; Pirinen et al., 2010). To date, only one study explicitly has evaluated the relation between abdominal pain and sleep disturbance in pediatric IBD (Benhayon et al., 2013). As previously described, Benhayon and colleagues demonstrated a positive association between abdominal pain and sleep disturbance in youth with depression and $\mathrm{CD}$. However, because this study utilized a sample with comorbid CD and depression, the results may not generalize to patients with UC or patients without depression. Thus, additional research regarding the relation of pain and sleep in pediatric IBD is warranted.

Although few studies have examined the association between pain and sleep in IBD, literature using pediatric chronic pain conditions and in particular, functional abdominal pain, serves as a basis of why pain is an important factor to consider in sleep disturbance. Using a sample of 25 children and adolescents (ages 10-17) with functional abdominal pain (FAP) and a sample of 15 age- and gender-matched healthy children, Haim and colleagues (2004) determined that a greater percentage of children with FAP reported having poor sleep (42\%) compared to healthy children $(0 \%)$. More specifically, children with FAP reported frequently awakening from sleep due to abdominal pain, as well as experiencing pain when trying to fall asleep. Interestingly, no differences were demonstrated between groups with regards to sleep patterns as assessed by 
actigraphy. This finding contradicts the results of other studies, which have demonstrated more night awakenings and decreased sleep efficiency as assessed by actigraphy among adolescents with chronic pain conditions (Palermo, Toliver-Sokol, Fonareva, \& Koh, 2007). However, Haim and colleagues noted that their study was underpowered to examine differences in objective sleep measurements, which may have accounted for their lack of significant group differences.

Additionally, a study by Huntley and colleagues (2007) investigated the association between sleep disturbance and pain while controlling for psychopathology (i.e., depression and anxiety disorder diagnoses) in 67 youth aged $8-15$ years with FAP compared to 80 healthy peers. Results revealed greater parent- and child-reported sleep disturbance, including poorer sleep quality, more nightmares, and more problems falling asleep and staying asleep, in youth with FAP than in healthy children. No differences in total sleep time were demonstrated, suggesting youth with FAP may have more disruptions in sleep quality rather than duration. Moreover, the authors determined having pain was significantly associated with increased sleep disturbance above and beyond the influence of psychopathology.

Taken together, the current literature indicates that pain is a critical factor to consider in the study of sleep in children and adolescents with IBD. Even though pain has only been examined in one study with pediatric $\mathrm{CD}$, studies of other chronic pain samples suggest that pain is associated consistently with subjective sleep disruptions. However, the literature evaluating the relation of pain to objective sleep disturbance have yielded mixed results, indicating that additional research needs to be conducted to clarify this relation. Furthermore, previous studies in pediatric sickle cell disease have demonstrated a cyclical relation between pain and sleep problems, in which greater pain severity during the day is associated with worse sleep at night and worse sleep at night is associated with greater pain severity the next day (Valrie, Gil, Redding-Lallinger, \& Daeschner, 
2007). Therefore, future research should investigate the association between pain and sleep problems in pediatric IBD using a prospective design to determine if Valrie and colleagues' (2007) results extend to other pediatric illness samples.

\section{Psychological Functioning}

Given the unique issues of pediatric IBD, such as embarrassment and intrusiveness regarding intestinal symptoms (Banez, \& Cunningham, 2009), much research has been conducted to examine the psychosocial functioning of these youth (Greenley et al., 2010; Mackner et al., 2013). Overall, the research has demonstrated that children and adolescents with IBD have higher rates of internalizing symptoms (i.e., depression and anxiety) than samples of healthy children and youth with other pediatric chronic illnesses. In addition, disease severity, stress, family functioning, and maternal psychopathology have been correlated with internalizing symptoms in these youth with IBD (Greenley et al., 2010; Mackner et al., 2013). Because sleep disturbances have been associated with both depressive and anxious symptomatology among healthy children and adolescents (Chorney, Detweiler, Morris, \& Kuhn, 2008), it makes sense that these associations may be present among youth with chronic medical conditions who have additional disease-related stressors.

Among youth with IBD, only one study has explored the relation between psychological functioning and sleep (Benhayon et al., 2013). The results revealed an association between subjective sleep disturbance and internalizing symptoms such that youth who reported more sleep problems also reported greater depressive and anxious symptoms. However, as previously noted, this study has a number of limitations, including limited generalizability to youth with UC or without a diagnosis of depression, use of subjective measures only, and use of a 
cross-sectional design that does not allow for conclusions regarding directionality or causality of associations.

An examination of the pediatric chronic pain literature again provides additional rationale investigating the interplay between internalizing disorders and sleep. For example, Palermo and colleagues (2007) assessed sleep and associated factors, such as depression and worry before bedtime, among a sample of 20 adolescents (ages 12 to 17) with FAP, chronic headaches, myofascial pain, or type 1 complex regional pain syndrome. The authors found a relation between greater worry before bedtime and depressive symptoms and greater subjective sleep problems; however, objectively measured sleep was not significantly associated with depression or worry. This lack of association between internalizing symptoms and actigraphy results may be due to the way in which the authors analyzed the data. The authors chose to compute average measures of objective sleep to analyze this association rather than evaluating the relation of sleep and psychological symptoms in a prospective design, as Valrie and colleagues (2007) did in their sample of children with sickle cell disease. A prospective design may capture more variability in sleep patterns and psychological symptoms, and thus, may yield different results. Using a larger sample of adolescents with pain that was not related to a chronic disease, Palermo and colleagues (2011) determined pre-sleep arousal but not depressive symptoms were associated with greater subjective sleep disturbance. In a study of 26 female adolescents aged 12 to 17 years with musculoskeletal pain, Meltzer and colleagues (2005) also demonstrated a positive correlation between internalizing symptoms (i.e., depression and anxiety) and daytime sleepiness, but not between internalizing symptoms and nighttime sleep. The authors explained that their sample did not differ from a healthy sample of adolescents on total sleep time and this lack of difference, 
coupled with the pain sample's low ratings of depression and anxiety, may have accounted for the lack of significant relation between internalizing symptoms and nighttime sleep.

Overall, youth with IBD may be at a greater risk for experiencing internalizing symptoms compared to their healthy peers and these symptoms may be related to more disrupted sleep. However, only one study has assessed the association between psychological symptomatology and sleep in pediatric IBD. Research from other pediatric chronic pain samples have produced mixed results regarding this relation, with some studies suggesting a significant relation exists (Palermo et al., 2007; Palermo et al., 2011) and other studies suggesting it does not (Meltzer et al., 2005). In addition, multiple methods of measuring sleep have been utilized (i.e., self-report measures, actigraphy), which may contribute to the discrepancies between studies. Given the limited literature, future research should continue exploring the association of internalizing symptoms and sleep in pediatric chronic medical conditions and specifically, in pediatric IBD, using a multimethod approach.

\section{Health-related Quality of Life}

Health-related quality of life (HRQOL) has been defined as "a broad multidimensional concept that usually includes self-reported measures of physical and mental health" (CDC, 2012). HRQOL is commonly measured in pediatric psychology studies to assess youth adjustment to having a chronic medical condition (Palermo et al., 2008). In terms of pediatric IBD, many studies identified and described factors associated with HRQOL (Greenley et al., 2010; Mackner et al., 2013). Findings from these studies reveal lower youth- and parent-reported HRQOL among children and adolescents with IBD compared to healthy peers. Moreover, corticosteroid use, greater disease severity, older age, ineffective coping skills, depression, and poor family functioning have been associated with worse HRQOL in these youth (Mackner et al., 2013). 
The association of sleep with HRQOL has been examined in several pediatric chronic medical conditions, including liver transplant recipients and juvenile idiopathic arthritis and juvenile dermatomyositis. For instance, Fredericks and colleagues (2012) assessed parent-reported sleep disturbance and HRQOL among 47 patients aged 2-17 years who had undergone liver transplants. Their results revealed that children who were reported to have sleep disturbance, especially periodic limb movements and daytime sleepiness, had lower parent-reported HRQOL. Additionally, lower child-reported school functioning was associated with more daytime behavioral sequelae (i.e., inattention and hyperactivity). Using a sample of 155 patients with either juvenile idiopathic arthritis or juvenile dermatomyositis (ages 8 to 16), another study demonstrated that sleep problems and fatigue were inversely related to HRQOL (Aviel et al., 2011). Specifically, greater parent- and child-reported sleep disruption and fatigue were associated with worse overall HRQOL and disease-specific quality of life. However, because both studies relied entirely on subjective measures, it is possible the associations were inflated due to shared-method variance and that utilization of objective measures may yield different results.

Although no studies have examined the relation between sleep disturbance and HRQOL in pediatric IBD, Marcus and colleagues (2009) evaluated subjective fatigue and HRQOL in a sample of 70 children with IBD and 157 healthy children (ages 10-17). Compared to healthy youth, children and adolescents with IBD reported significantly poorer HRQOL and greater fatigue. Greater fatigue also was associated with worse HRQOL among youth with IBD. Moreover, youth with more severe IBD reported greater fatigue and poorer HRQOL than those youth with more mild disease. The results of this study provide some indication that an association between sleep problems and HRQOL may exist in pediatric IBD as fatigue and sleep 
are closely linked. However, it is clear that future studies are needed to determine whether an actual relation between sleep disturbance and HRQOL exists in this population.

Additionally, one study has investigated the associations among sleep problems, pain, depression, functional disability, and HRQOL in adolescents with various chronic pain conditions, including sickle cell disease, chronic headache, and juvenile idiopathic arthritis (Palermo \& Kiska, 2005). Their results demonstrated that greater reported sleep disturbance was related to greater depressive symptoms, more frequent reports of pain, increased functional disability, and reduced social and emotional HRQOL. Furthermore, depressive symptoms accounted for a significant amount of the variance in sleep disruption after controlling for the effects of pain, functional disability, and HRQOL. The authors explained that because their study utilized a cross-sectional design, future research should be conducted to explore the prospective associations between sleep, HRQOL, pain, and mood in pediatric samples.

Previous research suggests that HRQOL is a critical factor to consider in the study of sleep of youth with IBD. Even though this association has not been examined in pediatric IBD, studies with other chronic illness groups suggest that HRQOL is associated consistently with sleep disruption. Lastly, Palermo and Kiska's study (2005) suggests that the interplay between pain, mood, and HRQOL may be important to consider when studying sleep disturbance and promoting healthy sleep habits in youth with chronic medical conditions, including IBD.

\section{Summary of Relevant Literature and Rationale for Current Study}

IBD is characterized by an abnormal immune response and gastrointestinal inflammation, and consists of both Crohn's disease and ulcerative colitis (CDC, 2014). Both disorders are marked by a number of symptoms, such as diarrhea, abdominal cramping and pain, rectal bleeding, weight loss, fever, delayed puberty, and osteoporosis (Kim \& Ferry, 2004). The course of IBD is 
unpredictable in nature, with periods of symptom flare-ups and disease quiescence (Banez \& Cunningham, 2009). Treatment for IBD includes medication (e.g., aminosalicylates and corticosteroids), maintaining a healthy diet that excludes foods known to trigger symptoms, and potentially surgery if complications occur (CCFA, 2014). Given the increasing incidence of IBD in youth (Benchimol et al., 2011), much research has emerged regarding psychosocial functioning and disease sequelae, such as fatigue, among individuals with IBD. However, few studies have examined the role of sleep in pediatric IBD.

Recent research has suggested there may be a bi-directional relation between sleep disruption and gastrointestinal inflammation in which patients with IBD have sleep problems and those sleep problems create additional inflammation (Swanson, Burgess, \& Keskavazian, 2011). This has spawned a number of studies with adult patients with IBD, which have demonstrated that sleep problems and associated daytime sequelae are common in this population (Ali et al., 2013; Ananthakrishnan et al., 2013; Burgess et al., 2010; Keefer et al., 2006; Graff et al., 2011; Graff et al., 2013; Ranjbaran et al., 2007a; Zimmerman, 2003). Among pediatric IBD samples, far less research has been conducted on sleep disturbance (Benhayon et al., 2013; Nachimas et al., 2006; Pirinen et al., 2010). The results of these studies indicated youth with IBD may be at risk for sleep disturbance, including poor sleep quality, night awakenings, and daytime sleepiness. Furthermore, a positive association between disease activity and sleep disruption was demonstrated in two of the studies (Benhayon et al., 2013; Pirinen et al., 2010) However, all three pediatric studies are limited by their use of subjective sleep assessments that can be influenced by an individual's biases. Thus, future research should consider using objective measures, such as PSG and actigraphy, to provide more accurate estimates of sleep patterns and disturbances in this population. 
In addition to describing sleep patterns using multiple methods, it is important to determine what factors are associated with sleep disturbance based on previous research examining functioning of youth with IBD and research exploring psychosocial factors with other pediatric chronic medical conditions. Such research has revealed that children and adolescents with IBD experience high rates of internalizing symptoms (i.e., depression and anxiety) and poor HRQOL (Greenley et al., 2010; Mackner et al., 2013). Studies using pediatric chronic pain samples also have linked greater internalizing symptoms and worse HRQOL to greater sleep disruption (Aviel et al., 2011; Palermo et al., 2007). Moreover, abdominal pain is common symptom of IBD and research with pediatric FAP has demonstrated a positive association between pain and sleep disturbance (Haim et al., 2004; Huntley et al., 2007). Therefore, it seems reasonable that the aforementioned factors would be related to sleep problems among youth with IBD.

However, only one study to date has evaluated the association between pain, psychological functioning, and sleep in pediatric IBD (Benhayon et al., 2013). The authors determined that youth who reported more sleep difficulties also reported greater depressive and anxious symptoms. Moreover, the results revealed an association between abdominal pain and sleep such that greater reports of pain were related to greater subjective sleep disturbance. Although this study added to the literature by examining factors related to sleep disruption in youth with IBD, it has a number of limitations, including limited generalizability to youth with UC or without a diagnosis of depression, use of subjective measures only, and use of a cross-sectional design that does not allow for conclusions regarding directionality or causality of associations. These limitations point to a need for future research using objective assessments, a prospective design, and a sample including both pediatric $\mathrm{CD}$ and $\mathrm{UC}$. 
Although no studies have explored the association between HRQOL and sleep in pediatric IBD, Marcus and colleagues (2009) found that poorer HRQOL was related to greater subjective fatigue among youth with IBD. These results suggest that more research needs to be conducted in this population, as fatigue and sleep are closely linked but are two separate constructs. Moreover, looking to the field of pediatric chronic pain provides rationale for investigating the interplay among sleep, pain, depression, and HRQOL. Using a sample of adolescents with various pain conditions, Palermo and Kiska (2005) demonstrated that greater depressive symptoms, more frequent reports of pain, and reduced social and emotional HRQOL were associated with more sleep disruption. Their results also indicated that depressive symptoms are strongly related to sleep disturbance after accounting for the effects of pain and HRQOL. However, given the crosssectional nature of Palermo and Kiska's (2005) study, additional research should utilize prospective designs to explore the associations between sleep, HRQOL, pain, and mood over time.

Taken together, the results of the aforementioned studies suggest that pain, disease activity, mood, and HRQOL may be important factors to consider in the investigation of sleep patterns and disturbances in children and adolescents with IBD. Moreover, these factors may be considered targets of future interventions designed to promote optimal sleep in this population. Therefore, the purpose of this study is to examine sleep patterns and associated factors, including pain, disease activity, mood, and health-related quality of life, in children and adolescents with IBD. More specifically, the specific aims and hypotheses of the current study are as follows:

Aim 1: To describe objectively measured sleep patterns, including total sleep time, sleep onset latency, sleep efficiency and wake after sleep onset, and subjective sleep habits among children and adolescents with IBD and compare to data from previously published studies using healthy samples. 
Aim 2: To examine the associations between subjective sleep patterns (1-week parent or 2-week patient retrospective report), objective sleep patterns (aggregated measures of total sleep time, sleep onset latency, sleep efficiency, and wake after sleep onset across 14-day study period), disease activity (at study enrollment), and health-related quality of life (2-week retrospective report) among children and adolescents with IBD. Based on previous research within samples of pediatric IBD and other chronic medical conditions (e.g., Benhayon et al., 2013; Pirinen et al., 2010), the following hypotheses were proposed:

- Hypothesis 2a: Youth who are rated by physicians as having greater disease activity will have greater subjective and objective sleep disturbance.

- Hypothesis 2b: Youth who report worse health-related quality of life will have greater subjective and objective sleep disturbance.

- Hypothesis 2c: Youth who have worse parent-reported health-related quality of life will have greater subjective and objective sleep disturbance.

Aim 3: To examine the associations between objective sleep patterns, abdominal pain, and negative affect across a 14-day period among children and adolescents with IBD. Based on previous research within samples of pediatric IBD and other chronic medical conditions (e.g., Benhayon et al., 2013; Gil et al., 2003; Pirinen et al., 2010; Valrie et al., 2007), the following hypotheses were proposed:

- Hypothesis 3a: Youth who report experiencing more intense pain during the day will have more objective sleep disturbance that night.

- Hypothesis 3b: Youth who have more objective sleep disturbance at night will report experiencing more intense pain the next day. 
- Hypothesis 3c: Youth who report more negative affect during the day will have more objective sleep disturbance that night.

- Hypothesis 3d: Youth who have more objective sleep disturbance at night will report experiencing more negative affect the next day.

Aim 4: To explore the association between objective sleep patterns and positive affect across a 14day period among children and adolescents with IBD.

- Hypothesis 4: Because there is no previous literature on the association of positive affect and sleep, this aim was exploratory and thus, no hypothesis was generated. 


\section{Method}

\section{Participants}

Fifty-one children and adolescents with IBD and their primary caregivers were approached regarding participation in the current study. Patients were recruited from West Virginia University's pediatric gastroenterology clinic or via recruitment letters sent to all patients on the gastroenterology clinic registry. This study included children and adolescents who: a) were between ages 10 and 18 years; b) had a diagnosis of Crohn's disease or ulcerative colitis for at least 3-4 months (to help ensure patients have been medically stabilized after initial diagnosis); c) were either currently experiencing disease activity or in a period of disease quiescence; and d) had a primary caregiver who was willing to participate with the patient. Patients who were judged to be unable to complete the study questionnaires were not recruited for the current study. Of those approached, 40 patients agreed to participate (22\% refusal rate). Reasons for refusal included lack of interest in the study $(n=4)$ and being too busy to complete study measures $(n=7)$. No significant differences in terms of patient age, gender, or race were demonstrated between participants and non-participants. Four additional participants withdrew from the study due to lack of interest. Ten participants did not complete the current study measures or actigraphy and were considered lost to follow-up. One participant was excluded from all analyses due to lack of selfreported bedtimes and wake times and inability to corroborate actigraphy data. Demographic data for the final sample of 25 youth are presented in Table 3. The mean age of patients was 14.25 years $(S D=2.42)$ and $56 \%$ of the patients were male. Primary caregivers who participated were primarily mothers $(88 \%)$. The majority $(80 \%)$ of participants was diagnosed with Crohn's disease and was in a state of disease remission (80\%). Participants who were rated as being in a state of 
disease remission did not significantly differ on demographic characteristics (i.e., age, gender, race, and ethnicity) compared to those who were rated as having active disease.

\section{Procedure}

During routine clinic appointments, potential participants were identified by healthcare staff and asked if they were interested in hearing about a research study. After participants agreed to hear about the study, a research assistant described the study's purpose and procedures as well as potential risks and benefits of participation in a private clinic room. The research assistant also discussed confidentiality and HIPAA guidelines with the family. If participants agreed to the study, the research assistant obtained informed consent from the patient's primary caregiver and patients aged 18; assent also was obtained from patients aged 8-18 In addition, a letter describing the study's purpose and procedures was mailed to all eligible patients and their families in the patient registry in an effort to recruit patients who do not attend clinic appointments regularly. Families were instructed to contact research staff by phone if interested in participating. A member of the research staff then scheduled an appointment to review the consent and assent forms and questionnaires either over the phone, at clinic, the family's home, or a mutually agreed upon public location. Phone numbers and/or email addresses of participating families were collected on the consent forms to contact them regarding reminders to complete study measures, to arrange to pick up study materials, if needed, and to contact families who won a gift card in the lottery at the end of the study. Of participants who completed the study, 23 were recruited in clinic, while three were recruited via mailings.

After being consented, each family was given a packet of questionnaires that are unrelated to the current study to complete at home and send back using pre-addressed, stamped envelopes. After these questionnaires were received, a research assistant mailed out an actigraph, instructions 
for actigraph use, a packet of questionnaires for participants to complete during the 14-day study period, and pre-addressed, stamped envelopes. This method was utilized to help determine the family's trustworthiness in returning study questionnaires and equipment. Research assistants also called or emailed participants after packets were sent out to review instructions for completing the questionnaires and wearing the actigraph (also referred to as "actiwatch"). Patients were instructed to wear the actigraph on their non-dominant wrist at all times, except during bath time or when the actigraph may be submerged in water (e.g., washing dishes, swimming), for 14 days following receipt of study packet. Patients (or parents, depending on patient's age) were instructed to depress a button on the actiwatch until it clicked at bedtime and upon awakening in the morning. The research assistant instructed families to consider the patient's "first opportunity to attempt to sleep alone" as bedtime/time to depress the actiwatch button at night. The research assistant also instructed families to consider the time at which the patient "awoke in the morning without going back to sleep" as the patient's wake time/time to depress the actiwatch button in the morning. In addition, families were instructed to complete the Sleep Diary with information regarding nighttime awakenings each morning. For the remainder of the daily measures (i.e., Sleep Diary nap information, Pain Diary, PANAS), patients were instructed to complete them as close to bedtime as possible in an effort to capture information from the entire day.

Within each questionnaire packet, the parents completed the following questionnaires on day 1 (Time 1): a) Family Information Form (may be have been completed with patient if appropriate); and b) Child Sleep Habits Questionnaire. Also at Time 1, the patients completed the following questionnaires: a) Pain \& Sleep Diary; b) Positive and Negative Affect Schedule for Children (PANAS-C); and c) Sleep Habits Survey. For days 2-13, patients completed the following measures in addition to wearing the actigraph: a) Pain \& Sleep Diary; and b) Positive and Negative 
Affect Schedule for Children. On day 14 (Time 2), both patients and parents completed the IMPACT-III. Table 1 displays the overall study flow. In addition to the questionnaire packets, the patient's physician completed either the Pediatric Crohn's Disease Activity Index or the Pediatric Ulcerative Colitis Activity Index, depending on the patient's diagnosis, when the patient was recruited in clinic. The physician was blinded to study data when completing the aforementioned measures of disease activity. The physician also reviewed the participants' medical charts and recorded dates of symptom flares in the year prior to recruitment date.

A research assistant called, emailed, and/or sent a text message (depending on family preference) to each family twice a week during the 14-day study period to remind them to complete the daily questionnaires and to answer any questions families had at the time. At the end of the study period, families mailed all questionnaires and actigraph equipment back to the WVU Department of Psychology using pre-addressed, stamped envelopes. If families did not mail the equipment back after completion of data collection, a research assistant called the family to arrange to pick up the study materials either at their home, in clinic, or a public location. For their participation in the study, families received up to $\$ 75$ in gift cards and cash. For completion of Time 1 questionnaires, patients and parents each received a \$10 gift card (total of \$20 in gift cards). In terms of days 2-13, patients were paid $\$ 2.50$ in cash for each day they completed the measures (i.e., Pain \& Sleep Diary, PANAS-C, actigraphy). Moreover, patients received an additional $\$ 5$ in cash if they completed all study measures during days $2-13$. Similar to Time 1 , patients and parents each received a $\$ 10$ gift card for completion of Time 2 questionnaires. In addition, families who returned the actigraphy equipment in working order were entered into a lottery to receive one of five $\$ 50$ gift cards (see Table 2 for schedule of participant remuneration). The lottery was conducted at the conclusion of all data collection. 


\section{Measures}

Family Information Form. The Family Information Form was created for this study to collect data on demographic and medical information about the patient and primary caregiver, such as patient and primary caregiver age, ethnicity, education level, and patient medical history. In addition, parents completed items on sleep health beliefs for their child and knowledge regarding sleep in youth that were based on questions from the Parental Knowledge of Healthy Sleep in Children (Owens, Jones, \& Nash, 2011).

Child Sleep Habits Questionnaire (CSHQ; Owens, Spirito, \& McGuinn, 2000). The CSHQ is a 35-item parent-report questionnaire that assesses the sleep habits of children during the past week. Although the $C S H Q$ was originally developed based on a sample of parents of children ages 4 to 10 years, it was completed by parents of all children in the current study. The CSHQ yields a total sleep disturbance score and eight subscales, including bedtime resistance, sleep onset delay, sleep duration, sleep anxiety, night wakings, parasomnias, sleep-disordered breathing, and daytime sleepiness. Parents rated their child's sleep on a 3-point Likert-type scale ("usually/5 or more times a week," "sometimes/2-4 times a week," and "rarely/0-1 times a week"). Parents also indicated whether each sleep habit was a problem or not and whether their child was "very sleepy" or "falls asleep" during various daytime activities (e.g., eating meals, riding in a car). Finally, parents listed the child's average bedtime and wake time, as well as average sleep duration on weekends and weekdays and average duration of night awakenings across the one-week period. Several items are reverse-scored, so higher scores indicated greater sleep disturbance. Subscales are calculated by summing relevant items, and the total sleep disturbance score is the sum of all subscales. Owens and colleagues (2000) reported high specificity and sensitivity for distinguishing between children with sleep disorders and those without sleep disorders. 
For the current study, all subscales and the total sleep disturbance score were calculated to describe the patient's sleep habits. In addition, average total sleep duration and night awakening duration during the past week was calculated to provide descriptive information for the sample. Within the current study, internal consistency for the total sleep disturbance was .68. Internal consistency for $C S H Q$ subscales ranged from .08 (daytime sleepiness) to .82 (night wakings).

Pain \& Sleep Diary. The Pain \& Sleep Diary was created for this study to collect data on each patient's daily pain and sleep throughout the 14-day study period. Patients rated their abdominal pain intensity each day on a 0 to 10 Likert-type scale with $0=$ "no pain" and $10=$ "worst pain ever." Patients also completed items regarding time and duration of night awakenings and daytime naps to corroborate data gathered from the actiwatches. In addition, planned wake time, reasons for nighttime awakenings, use of corticosteroids, as well as times of taking the actiwatch off and putting it back on were recorded in the diary.

Positive and Negative Affect Schedule for Children (PANAS-C; Laurent et al., 1999). Patients completed the $P A N A S-C$ to assess positive and negative affect daily. The $P A N A S-C$ was specifically chosen because it assesses multiple dimensions of mood (including sadness and anxiety, which have been examined in previous literature [e.g., Benhayon et al., 2013], as well as positive aspects of mood, such as happiness) and is a self-report measure that can assess changes in mood on daily basis. The PANAS-C consists of 30 items, 15 assessing positive affect and 15 assessing negative affect. Patients rated their mood using different words (e.g., happy, sad, nervous) on a 5-point Likert-type scale from 1 = "very slightly or not at all" to 5 = "extremely." This questionnaire yields both positive and negative affect scores. To score each scale, the sum of the items for that scale was calculated. Higher scores equal greater negative or positive affect. Previous studies indicate the $P A N A S-C$ has good discriminant and convergent validity with 
self-report, validated measures of anxiety and depression among children in grades 4 through 8 (Laurent et al., 1999). In addition, this measure has been previously utilized in youth ages 11 to 20 with sickle cell disease (Zempsky et al., 2013). For this study, both positive and negative affect scores were utilized. Cronbach's alpha coefficients varied by day across the 14-day study period and ranged from .72 (on day 3 ) to .95 (on day 14) for negative affect and .81 (on day 11) to .96 (on day 3) for positive affect.

Sleep Habits Survey (SHS; Wolfson \& Caskadon, 1998). Youth completed the SHS to assess their perceptions of their sleep habits during the previous two weeks. The SHS is a 63-item measure of sleep habits and school performance; however, only the 40 items assessing sleep habits were utilized for this study. The SHS includes items that measure total sleep time, bedtime, and wake time on weekdays and weekends, as well as three subscales (sleepiness scale, sleep/wake problems scale, and morningness/eveningness scale). On the sleepiness scale, patients rated their level of sleepiness during various activities on a 4-point Likert-type scale (1 = "no sleepiness" to 4 $=$ "struggled to stay awake or fell asleep"). Higher scores indicate greater daytime sleepiness. Patients also rated the frequency of their problems with sleeping and waking from $1=$ "never" to 5 $=$ "everyday," with higher scores indicating greater sleep and wake problems. Lastly, patients completed the morningness/eveningness scale, which presents different scenarios to determine sleepiness and alertness in the morning versus evening. Higher scores indicate a morning preference while lower scores indicate an evening preference. Wolfson and colleagues (2003) found moderate to high correlations between the $S H S$ and sleep diaries and actigraphy, indicating good convergent validity. For the current study, all three subscales were calculated to describe youth-reported sleep habits (i.e., sleepiness scale, sleep/wake problems scale, and morningness/eveningness scale). In addition, average total sleep time during the previous two 
weeks was calculated for the sample. In the current study, the $S H S$ demonstrated variable internal consistency for the subscales (i.e., sleepiness scale $=.55$, sleep/wake problems scale $=.80$, and morningness/eveningness scale $=.72$ ).

Pediatric Crohn's Disease Activity Index (PCDAI; Hyams et al., 1991). The PCDAI is a physician-report assessment of disease activity of children and adolescents with Crohn's disease. The $P C D A I$ is a 12 -item questionnaire that assesses several domains related to disease activity in Crohn's disease, including abdominal pain, stools, patient general well being, laboratory values, and physician examination questions. Scores on the abdominal pain, stools, and patient general well-being items range from 0 (“no/minimal problems") to 10 ("severe problems”). Laboratory values are converted to a scoring system ranging either from 0 to 5 or 0 to 10 . The physician examination items assess patient height, weight, tenderness of abdomen, perirectal disease, and extraintestinal manifestations, and can be categorized as 0,5 , or 10 . Items are summed to create a total disease activity score. Total scores range from 0 to 100 , with higher numbers corresponding to greater disease activity. Patients can be categorized as having "inactive disease" (scores less than 10), "mild disease" (scores of 11-30), or "moderate to severe disease" (scores greater than 30). Studies of the PCDAI reveal good specificity and sensitivity for identifying periods of moderate or severe disease activity among youth aged 8 to 15 (Hyams et al., 2005). Patients were categorized into three aforementioned groups for subsequent analyses.

Pediatric Ulcerative Colitis Activity Index (PUCAI; Turner et al., 2007). The PUCAI is a physician-report assessment of disease activity of children and adolescents with ulcerative colitis. The PUCAI is a 6-item questionnaire that assesses six disease activity domains: abdominal pain, rectal bleeding, stool consistency, number of stools per day, nocturnal stools, and activity level. Abdominal pain, stool consistency, and activity level items are rated on a 3-point scale $(0,5,10)$, 
while the items related to rectal bleeding and number of stools are rated on a 4-point scale $(0,10$, 20,30 or $0,5,10,15$, respectively). Finally, the nocturnal stools item is rated as either 0 or 10 . All items are summed to create a total disease activity score that ranges from 0 to 85 , with higher scores indicating greater disease activity. Patients can be categorized into one of four groups: a) “disease remission" (scores less than 10), b) "mild disease" (scores of 10-34), c) "moderate disease" (scores of 35-64), and d) "severe disease" (scores greater than 65). For the current study, the categories of "moderate disease" and "severe disease" were combined into one group to enable consistency across the PCDAI and PUCAI: "moderate to severe disease" (scores greater than 35). The PUCAI has demonstrated good inter-observer reliability $(\mathrm{ICC}=.95)$ and convergent validity with other assessments of disease activity, such as colon appearance measured via colonoscopy, in samples of youth ages 3 to 18 years (Turner et al., 2007). Disease activity was analyzed using three categories of "remission," "mild," and "moderate to severe" disease.

Actigraphy (Mini Mitter Actiwatch-64; Bend, Oregon). The Mini Mitter Actiwatch-64 is a wristwatch-like device used to assess sleep/wake patterns. The actiwatch measures sleep/wake patterns by using an accelerometer to monitor movement. The actiwatch was worn on the patient's non-dominant wrist for 14 consecutive days. Patients (or parents, depending on the patient's age) pressed a button on the actiwatch at bedtime and upon awakening in the morning, which places an event marker within the data being collected. The actiwatch was programmed to the 30 -second epoch setting to allow for continuous monitoring during the 14-day study period. Based upon the movement data, several sleep-related measurements were determined using the Actiwatch software: a) sleep onset; b) sleep onset latency (i.e., time between reported bedtime and sleep onset); c) wake time; d) wake after sleep onset (i.e., minutes awake during sleep period); e) total sleep time (i.e., duration between sleep onset and wake time minus duration of wake after sleep 
onset); and f) sleep efficiency (i.e., total sleep time divided by time in bed) (Meltzer et al., 2012).

Sleep onset latency, total sleep time, sleep efficiency, and wake after sleep onset were used in analyses.

A review of the literature on actigraphy use in pediatric samples determined that actigraphs have high sensitivity for identifying sleep and low specificity for identifying wake after sleep onset in comparison to polysomnography, videosomnography, and direct observation (Meltzer et al., 2012). More specifically, studies using samples of ages similar to that of the current study and the Actiwatch-64 found sensitivities ranging from 78.1 - 96.5 and specificities ranging from 39.4 52.6 (Hyde et al., 2007; O’Driscoll et al., 2009). However, actigraphy provides an objective method of assessing sleep/wake patterns that is more ecologically valid than the "gold standard" of sleep assessment, that being polysomnography.

IMPACT-III (Otley et al., 2002; Otley et al., 2006). The IMPACT-III is a health-related quality of life measure designed for use in children and adolescents (ages 9 to 18 years) with IBD over the past two weeks. The IMPACT-III is a 35-item scale that assesses six areas of quality of life: bowel symptoms, systemic symptoms, emotional functioning, social functioning, body image, and treatment interventions. Patients rated their quality of life for each subscale using a 5point Likert-type scale. Scores are transformed from $0-5$ to a $0-100$ scale for interpretation ( 0 $=100,1=75,2=50,3=25,4=0$ ), with higher scores corresponding to greater quality of life. A total quality of life score and six individual domain scores can be obtained by computing the mean score of either all the questions answered (total score) or the mean score of the questions answered under the individual domain (individual domain scores). The IMPACT-III was responsive to change in quality of life based on disease activity (Otley et al., 2006). A previous version of the IMPACT-III demonstrated convergent validity with other measures of quality of 
life (Otley et al., 2002). For the current study, this measure was adapted to create a parent-report version so parents also could provide proxy ratings of their child's quality of life. Only the total quality of life score (parent and patient report) was used for study analyses. The IMPACT-III demonstrated high internal consistency for both the patient- and parent-report versions in this study ( $\alpha=.91$ and .93 , respectively). 


\section{Results}

All statistical analyses were conducted through use of Predictive Analytics Software and Solutions version 21 (SPSS 21).

\section{Power analyses.}

Statistical power for multilevel modeling approaches is based on the number of observations rather than the number of persons and allows for detection of effects using small sample sizes (Curran, Obeidat, \& Losardo, 2010;Schwartz \& Stone, 1998). Using a sample of 37 adolescents with sickle cell disease, Gil and colleagues (2003) found medium to large effect sizes for the association of negative $\operatorname{mood}(\beta=0.36, t=8.55, p<.0001)$ and positive $\operatorname{mood}(\beta=-0.4, t$ $=-10.09, p<.0001)$ to same-day pain. In addition, Valrie and colleagues (2007) found a large effect size for the relation of sleep quality to pain severity in a sample of 20 children with sickle

cell disease $(\beta=-6.54, t=-8.18, p<.01)$. Moreover, results of Benhayon and colleagues' (2013) study of adolescents with CD revealed medium to large effect sizes regarding the association of sleep disturbance with disease activity $\left(R^{2}=21.6, p<.0001\right)$, anxiety $\left(R^{2}=8.6, p=.005\right)$, and abdominal pain $\left(R^{2}=15.7, p=.0001\right)$. Because the aforementioned studies used multilevel modeling techniques to examine variables similar to those in the current study, it is assumed that effect sizes in this study will be comparable. Therefore, this study aimed to recruit approximately 25-30 participants to detect a medium to large effect size.

\section{Preliminary analyses.}

All participants with at least seven days of diary and actigraphy data including both weekdays and weekends were retained in the final sample for analyses. First, all data were reviewed to locate any missing data for Aims 1 and 2, and to ensure that all missing data were random. Review of data revealed minimal amounts of missingness across study variables. Two 
participants were missing data from the entire $C S H Q$ and one participant was missing data from the entire SHS. These participants were excluded for relevant analyses in aim 2. Person-mean imputation (i.e., substituting the participant's mean score of completed items on a scale for the items that were not completed) was utilized to address missingness for questionnaire data (i.e., SHS, CSHQ, IMPACT-III) for other participants (all who had less than $10 \%$ missing data). Imputation was not utilized to address missingness among diary data, $P A N A S-C$, and actigraphy given that these data were examined utilizing multilevel modeling. Multilevel modeling allows for the analysis of unequal amounts of data and includes methods for handling missing data, such as multiple imputation and maximum likelihood estimations (Schwartz \& Stone, 1998).

Next, study variables were examined for skewness, kurtosis, and outliers. These analyses revealed 5 outliers and 5 kurtoic variables $(C S H Q$ bedtime resistance subscale, $C S H Q$ sleep anxiety subscale, $C S H Q$ parasomnias subscale, $C S H Q$ sleep disordered breathing subscale, $S H S$ sleep-wake problems subscale). No skewed variables were revealed. To attempt to correct these issues, square root, log, and inverse transformations were performed. These transformations corrected the outlier and kurtoic issues among three variables (CSHQ bedtime resistance subscale, $C S H Q$ sleep anxiety subscale, $S H S$ sleep-wake problems subscale) and these transformed variables were utilized in subsequent analyses. However, none of the transformations corrected the kurtosis or outlier issues for $C S H Q$ parasomnias and $C S H Q$ sleep disordered breathing subscales and therefore, the variables were retained in their original form. Descriptive statistics for all primary study variables are presented in Table 4. Additionally, frequency information for the parental beliefs and sleep knowledge questions from the FIF are presented in Table 5. 


\section{Aim 1.}

The first aim was to describe objectively measured sleep patterns and subjective sleep habits. First, objective sleep data were aggregated across the 14-day study period for each participant using the four variables of interest (i.e., total sleep time, sleep onset latency, sleep efficiency, and wake after sleep onset). Next, means and standard deviations of each objective sleep variable and subjective sleep measures $(C S H Q$ and $S H S)$ were computed across participants (see Table 4 for complete descriptive information).

Objective and subjective sleep patterns also were compared to sleep patterns among samples of healthy youth from previously published studies (i.e., Meltzer, Walsh, Traylor, \& Westin, 2012; Owens, Spirito, \& McGuinn, 2000; Wolfson \& Carskadon, 2003) using $t$-tests. Compared to normatively developing youth (Owens, Spirito, \& McGuinn, 2000), youth with IBD had significantly greater sleep duration $(t=3.49, p=.002)$, night wakings $(t=2.71, p=.013)$, and daytime sleepiness $(t=8.41, p<.001)$ as reported on the $C S H Q$. Regarding actigraphy data, children and adolescents in the current study experienced significantly lower total sleep duration $(t$ $=-2.13, p=.043)$, less wake after sleep onset $(t=-3.18, p=.004)$, and greater sleep efficiency $(t$ $=3.04, p=.006$ ) compared to healthy samples (Meltzer, Walsh, Traylor, \& Westin, 2012). No significant differences were demonstrated on the $S H S$ and other $C S H Q$ subscales (see Table 6).

\footnotetext{
Aim 2.

To examine the associations between sleep patterns, disease activity, and health-related quality of life, Pearson correlation coefficients were conducted with mean objective sleep variables, mean subjective sleep variables, mean parent- and child-reported HRQOL (IMPACTIII), and patient age. Pearson correlation coefficients also were calculated using the mean square successive difference of each of the four objective sleep variables of interest (to assess
} 
night-to-night instability in sleep patterns), mean parent- and child-reported HRQOL (IMPACTIII), and patient age. The procedure for calculating mean square successive differences involved subtracting the value of each night (e.g., total sleep time) from the value of the next night and then squaring the difference for each individual in the study (Jahng, Wood, \& Trull, 2008). In addition, Spearman correlations were conducted with disease activity categories (i.e., "remission," "mild," and "moderate to severe" disease), mean objective sleep variables, mean subjective sleep variables, and mean square successive differences of objective sleep variables. Moreover, Mann-Whitney $U$ tests were calculated to determine if there were any significant differences in sleep variables between participants in a state of disease remission and participants experiencing active disease.

Results revealed that older youth experienced lower objective total sleep duration $(r=$ $.502, p=.011)$. Given this significant finding, partial correlations controlling for patient age were conducted to examine associations among objective total sleep duration, mean parent- and childreported HRQOL (IMPACT-III), and disease activity categories; however, no significant associations emerged. Children and adolescents who reported having a higher morning preference on the SHS morningness/eveningness subscale reported greater HRQOL $(r=.485, p=.016)$. Youth who experienced greater disease activity had more variable wake after sleep onset as recorded via actigraphy $(\rho=.582, p=.002 ; U=2.853, p=.002)$. All other correlations and group comparisons were non-significant (see Tables 7 and 8 for full correlation tables).

\section{Aim 3.}

Multilevel modeling with restricted maximum likelihood estimation was utilized to analyze the temporal patterns of objective sleep patterns, abdominal pain, and negative affect across the 14day study period. Separate models were conducted to examine the associations of sleep and pain, as well as sleep and negative affect. For each model, objective sleep patterns and abdominal pain 
or negative affect were estimated as the within-person factors. Pain and negative affect scales were partialed into their overall average and person-centered components. This allows for the "average" portion to be interpreted similar to an ordinary least square regression as an estimate of betweenperson effects. The person-centered component estimates the deviation from each person's average and represents within-person change. Disease activity and patient age were estimated as the between-persons factors to determine if there are differences in the associations based upon whether a person is experiencing a symptom flare or is in a period of disease remission and any differences by age. To examine the hypotheses that youth who report more intense pain and negative affect during the day will have more objective sleep disturbance at night (hypotheses 3a and 3c), pain and negative affect variables were estimated to predict sleep that night. In addition, sleep variables were estimated to predict next-day pain and negative affect in order to determine if youth who have more objective sleep disturbance report more intense pain or negative affect the next day (hypotheses 3b and 3d).

Models of abdominal pain predicting sleep onset latency, sleep efficiency, wake after sleep onset, and total sleep time were designated as models A, B, C, and D, respectively, while the model of objective sleep variables (i.e., sleep onset latency, sleep efficiency, wake after sleep onset, and total sleep time) predicting abdominal pain was designated as model E. Additionally, models of negative affect predicting sleep onset latency, sleep efficiency, wake after sleep onset, and total sleep time were labeled models F, G, H, and I, respectively, while the model of objective sleep variables predicting negative affect was labeled model J. For the majority of multilevel models predicting sleep variables and negative affect or pain (i.e., models B, C, E, F, G, H, I, and J), a "Hessian" error occurred at the random effects level, indicating that the model was not a positive definite and did not converge due to lack of variability in the random effects (i.e., 
individuals do not differ in association of pain or negative affect and sleep). However, removal of the person-centered components of pain, negative affect, and sleep variables addressed the nonconvergence issue and analyses were conducted without these variables at the random effects level. The random effects of models $\mathrm{B}, \mathrm{C}, \mathrm{D}, \mathrm{G}, \mathrm{H}$, and I demonstrated that there is significant within person and between person variation in sleep variables to be accounted for in future models (see Tables 9 and 11 for full model information). The random effects of models $\mathrm{E}$ and $\mathrm{J}$ also revealed that there is significant within-person and between-person variation in pain and negative affect, respectively, to be accounted for in future models (see Tables 10 and 12 for full model information). There were no significant random effects for any person-centered pain, negative affect, or sleep variables, indicating that these variables function the same way across individuals. In terms of fixed effects, patient age was a significant predictor of total sleep time in models $\mathrm{D}$ and I. Specifically, increased age was associated with decreased total sleep time $(B=-12.40, p=.008$ for model $\mathrm{D} ; B=-11.74, p=.013$ for model I).

Finally, the association of night-to-night instability in objective sleep patterns, abdominal pain, and negative affect was examined using multilevel modeling. The square successive difference of each sleep variable was utilized as a within-persons factor along with abdominal pain and negative affect, and disease activity and patient age as the between-persons factors. For each multilevel model predicting night-to-night sleep instability and negative affect or pain, a "Hessian" error occurred suggesting that the model did not converge and there was not significant change in sleep instability, pain, or affect scores over time. Removal of person-centered variables and the intercept from the random effects level did not correct the non-convergence error. Thus, the multilevel model could not be applied and no further analyses were conducted. 


\section{Aim 4.}

The fourth aim was to explore the associations between objective sleep patterns and positive affect across time. Again, multilevel modeling was utilized to analyze the temporal patterns of sleep and positive affect across the 14-day study period. Objective sleep patterns and positive affect were utilized as the within-person factors and disease activity and patient age were utilized as the between-persons factors for this aim. Similar to Aim 3, positive affect was partialed into its overall average and person-centered component. Positive affect was estimated to predict sleep that night and sleep variables were estimated to predict next-day positive affect.

Models of positive affect predicting sleep onset latency, sleep efficiency, wake after sleep onset, and total sleep time were designated models $\mathrm{K}, \mathrm{L}, \mathrm{M}$, and N, respectively, while the model of objective sleep variables (i.e., sleep onset latency, sleep efficiency, wake after sleep onset, and total sleep time) predicting positive affect was designated model O. For the majority of multilevel models predicting sleep variables and positive affect (i.e., models L, M, N, and O), a nonconvergence "Hessian" error occurred at the random effects level. However, removal of the person-centered components of positive affect and sleep variables addressed the non-convergence issue and analyses were conducted without these variables at the random effects level. The random effects of models L, M, and $\mathrm{N}$ demonstrated that there is significant within person and between person variation in sleep variables to be accounted for in future models (see Table 13 for full model information). The random effects of model $\mathrm{O}$ also showed that there is significant within person and between person variation in positive affect to be accounted for in future models (see Table 14 for full model information). There were no significant random effects for any personcentered positive affect or sleep variables, indicating that these variables function the same way 
across individuals. In terms of fixed effects, increased patient age was associated with decreased total sleep time in model $\mathrm{N}(B=-12.07, p=.015)$.

In addition, the association between the square successive differences of each objective sleep variable and positive affect was examined using multilevel modeling. For each multilevel model predicting night-to-night sleep instability and positive affect, a "Hessian" error occurred suggesting that the model did not converge and there was not significant change in sleep instability or affect scores over time. Removal of person-centered variables and the intercept from the random effects level did not correct the non-convergence error. Thus, the multilevel model could not be applied and no further analyses were conducted. 


\section{Discussion}

The current study had the following aims: 1) to describe objectively measured sleep patterns and subjective sleep habits among children and adolescents with IBD and compare to published studies using healthy samples; 2) to examine the associations between subjective sleep patterns, objective sleep patterns, disease activity, and HRQOL among children and adolescents with IBD; 3) to examine the associations between objective sleep patterns, abdominal pain, and negative affect across a 14-day period among children and adolescents with IBD; and 4) to explore the association between objective sleep patterns and positive affect across a 14-day period among children and adolescents with IBD. Contrary to hypotheses, no significant associations were demonstrated among objective sleep variables (i.e., total sleep time, sleep onset latency, wake after sleep onset, and sleep efficiency), abdominal pain, and negative affect. Additionally, positive affect was not significantly associated with objective sleep patterns. However, youth in the current study demonstrated significant differences in subjective and objective sleep compared to data on normatively developing peers from previously published articles. Associations between sleep variables and patient age, disease activity, and HRQOL also were exhibited.

Previous research has demonstrated a significant positive association between pain and sleep difficulties among youth with IBD (Benhayon et al., 2013) and FAP (Haim et al., 2004; Huntley et al., 2007; Palermo et al., 2007). However, the current study revealed no such association, which may be due to a number of differences between the current study and previous literature. First, prior research determined this association by comparing children and adolescents with IBD or FAP to healthy youth on sleep variables rather than examining the association of sleep and pain within the illness group. It may be that this association is more pronounced when comparing different groups rather than comparing within a group. Additionally, the majority of 
previous research utilized samples of youth with FAP rather than pediatric IBD. Pain experienced by youth with FAP may be a different quality than that of children and adolescents with IBD given that IBD is characterized by gastrointestinal inflammation unlike FAP (Banez, \& Cunningham, 2009). Benhayon and colleagues' study also is different from the current study in that they utilized a sample of youth with CD only and subjective sleep measures, while this study included both pediatric $\mathrm{CD}$ and $\mathrm{UC}$ and used objective sleep measurement (i.e., actigraphy) to examine the association of sleep and pain. Therefore, it is possible this previously demonstrated association might be accounted for by disease group differences or shared method variance.

Another potential explanation for these contradictory findings regarding pain and sleep, as well as for disease activity and sleep is the lack of variability in disease activity within this sample. In fact, the majority of patients ( $80 \%$ ) were rated by their physicians as being in a state of disease remission or inactivity. The remaining $20 \%$ of participants were rated as experiencing mild disease activity, while $0 \%$ of participants experienced moderate or severe disease activity. This distribution is in stark contrast to Benhayon and colleagues' study (2013), in which $68 \%$ of participants were experiencing disease activity. Because periods of disease remission/inactivity are marked by minimal physical symptoms such as pain (CCFA, 2014), it is possible that participants did not experience much abdominal pain throughout the study. Indeed, the average pain rating across the study was 0.93 out of 10 and participants reported pain levels of greater than 1 on only $24 \%$ of diary days. Thus, more variability in disease activity and pain may be necessary to produce significant associations among these variables and sleep. Future research should aim to include more heterogeneous samples of pediatric IBD to further elucidate the associations between IBD symptomatology and sleep disturbance. For example, future studies might employ more specific inclusion criteria regarding disease activity or pain severity (e.g., include only patients who are 
rated as experiencing a symptom flare). Studies may also consider using ecological momentary assessment (EMA) to evaluate pain and other variables (e.g., mood) in real time and increase data variability rather than rely on written diaries where participants potentially complete pain and mood ratings at the end of the data collection period thereby providing inaccurate ratings (Shiffman, Stone, \& Hufford, 2008).

The lack of relation between affect and sleep also was unexpected given previous research suggesting an association between sleep and aspects of psychological functioning (e.g., Benhayon et al., 2013; Palermo et al., 2007). One reason for this finding may be the differences in measurement of psychological functioning. Prior studies specifically examined measures of depression and anxiety (e.g., Revised Child Anxiety and Depression Scale in Palermo and colleagues' study); however, the current study utilized a more general measure of mood (i.e., PANAS-C). It may be that such internalizing symptoms (i.e., depression, anxiety) are more closely linked with sleep than broad-based negative affect. Although the PANAS-C contains items assessing aspects of depression (e.g., sad, lonely) and anxiety (e.g., feeling jittery, afraid), the association of these specific items with sleep may have been reduced by aggregating all negative affect items into a subscale. Examination of the association of the aforementioned individual items of the PANAS-C and sleep may have revealed more significant findings. Benhayon and colleagues' (2013) study also only included youth with comorbid CD and depression, so their results may not generalize to the current sample, as participants were not screened for depressive symptomatology and likely did not exhibit significant levels of depressive symptoms. Moreover, the PANAS-C may not account for the unique psychological issues present within pediatric IBD, including intrusiveness and anxiety about gastrointestinal symptoms (Banez, \& Cunningham, 2009). Instead, a recently developed measure of gastrointestinal-specific anxiety, the Visceral Sensitivity Index 
(Labus et al., 2004), may better assess the psychological concerns of this population.

Gastrointestinal-specific anxiety might demonstrate a significant association with disrupted sleep and thus, should be examined in future studies.

While previous research has demonstrated a significant relation between sleep and HRQOL among various pediatric chronic illness populations (Aviel et al., 2011; Palermo \& Kiska, 2005), this study's findings did not support previous findings. The absence of a significant association may be due to differences between disease groups (e.g., symptom characteristics and frequency, type of treatment and course) because this is the first study to assess the relation between nighttime sleep and HRQOL within pediatric IBD. However, the current study findings also are inconsistent with Marcus and colleagues' (2009) results regarding daytime fatigue and HRQOL. These conflicting results may be a function of different time frames and administration time points of study measures. For example, the IMPACT-III and SHS refer to a two-week time period, while the CSHQ assesses sleep over a one-week time period. The $S H S$ and $C S H Q$ also were administered on day 1 , while the IMPACT-III was administered on day 14 (see Table 1 for study timeline). For example, it is possible that HRQOL on day 14 is correlated with sleep disruption at day 14 , but this association was not captured by the current study given the different administration points. Moreover, aggregating the objective sleep variables across the 14-day study period to enable comparison with the IMPACT-III eliminated the within-person sleep variability and potentially reduced the association between these variables.

Although some of the study hypotheses were not supported, a few interesting significant findings emerged. Consistent with Pirinen and colleagues' study (2010), parents reported that their children experienced greater sleep disruptions (specifically night wakings and daytime sleepiness) as compared to healthy youth from previously published studies. In addition, no differences in 
youth-reported sleep disturbance were reported in either study. However, the current study's results regarding actigraphic sleep contradict findings of a previous study of adolescents with various chronic pain conditions (Palermo et al., 2007). More specifically, Palmero and colleagues determined that adolescents with chronic pain experienced lower sleep efficiency and more night wakings than normatively developing peers, while the current study found greater sleep efficiency and less wake after sleep onset when compared to data from published articles using samples of healthy youth. Inconsistencies in study results may be due to sample differences as the current study involved a sample of pediatric IBD while Palmero and colleagues utilized a sample of various chronic pain conditions. Palermo and colleagues' sample also reported significantly higher levels of pain (mean usual pain $=6.6$ out of 10 ) than the current sample, which may account for the differences in findings. Additionally, given the high number of statistical analyses that were conducted, one cannot discount the possibility that this study's findings are the result of type I error and may be spurious.

Furthermore, this study revealed that older youth experienced lower actigraphic total sleep duration, which conflicts with prior pediatric IBD research (Nachmias et al., 2006) but aligns with research of normatively developing samples (e.g., Wolfson \& Carkadon, 1998). It may be that differences in measurement of sleep accounted for the discordant findings. Specifically, Nachmias and colleagues utilized a self-report sleep questionnaire, which may have resulted in inaccurate estimates of sleep due to social desirability bias or participants being poor historians of their own sleep. Regarding the association of disease activity and sleep among youth with IBD, mixed results have been demonstrated with some studies revealing that greater disease activity correlated with greater sleep disturbance (Benhayon et al., 2013) and others finding no such association (Nachmias et al., 2006). The current study adds to the literature base by providing additional evidence for the 
potential negative association between sleep and disease activity as increased instability in wake after sleep onset was demonstrated among youth experiencing more active disease. Lastly, morningness preference (i.e., preference for completing cognitive and physical activities during the morning time as opposed to afternoon or evening) was positively associated with better HRQOL. Randler (2011), who demonstrated similar results among a sample of normatively developing adolescents, postulated that morningness may serve as a protective factor against a host of emotional and physical health problems. It may be important for clinicians to screen for morningness/eveningness preference during routine clinic visits in effort to identify youth with IBD who are at risk for greater psychosocial issues. However, as mentioned previously, these results may be influenced by type 1 error and should be interpreted with caution.

The current results should be considered in the light of study limitations. First, the current sample included children and adolescents spanning a wide age range (i.e., 10-18 years). Although use of this age range allows for increased generalizability of results, there are drastic changes regarding sleep patterns that occur between childhood and adolescence. Specifically, decreasing sleep duration, slow wave sleep, and latency to REM sleep have been correlated with increasing age among youth (Ohayon, Carskadon, Guilleminault, \& Vitiello, 2004). Such differences in sleep patterns were reflected in this study's results in that older youth experienced less objective total sleep time. However, some age-related correlations may have been reduced within the current study due to the small sample size. Future studies that include a larger sample size of youth with IBD should be conducted to replicate these results and determine if any additional age-related associations exist within this population. Although the study's sample size should provide enough statistical power to detect medium to large effects based on previous literature that used similar statistical techniques and examined similar constructs, it is possible the results were impacted by 
type II error and the study was underpowered to detect significant associations. Thus, additional research using larger sample sizes of youth with IBD may yield hypothesized associations among sleep, pain, and mood.

The current study also had a number of measurement issues that may have impeded results. For example, both the $S H S$ and $C S H Q$ demonstrated substandard internal consistency on several subscales. As a result, it is possible that these questionnaires did not measure the same underlying construct (i.e., sleep patterns) and impacted the study findings. The low internal consistency of the CSHQ and SHS subscales may be due to these measures being developed and validated for different age ranges (i.e., 4-10 years for CSHQ and 13-19 years for SHS) than the current sample (i.e., 10-18 years). However, the aforementioned measures were chosen because they are both assess multiple dimensions sleep dysfunction (e.g., daytime sleepiness, sleep/wake schedules), utilize Likert-type scales that allow for increased response variability (rather than yes/no format of other measures such as the Pediatric Sleep Questionnaire; Chervin et al., 2000), and assess a relatively short time period (i.e., 1-2 weeks retrospective report rather than 3-6 months retrospective report). Although the child version of IMPACT-III has been well validated for use in pediatric IBD (Otley et al, 2002; Otley et al., 2006), the parent version of this questionnaire has not been validated. Future studies may want to employ more rigorous psychometric testing of the parent proxy IMPACT-III as it has demonstrated promising results in terms of reliability (i.e., excellent internal consistency within the current study) and concordance with the child version (Gallo et al., 2014). Moreover, a parent proxy measure of HRQOL may be a desirable clinical tool if youth have cognitive or other limitations (e.g., too fatigued or ill) that preclude use of a selfreport form (Eiser \& Morse, 2001). Finally, actigraphy is not considered the "gold standard" for sleep assessment. More specifically, actigraphs have demonstrated high sensitivity for identifying 
sleep, but low specificity for identifying wake after sleep onset (Meltzer et al., 2012). It is possible that actigraphy may not have accurately identified certain aspects of sleep disturbance in the current study (e.g., wake after sleep onset, sleep efficiency) and impacted study results.

In conclusion, some of the study hypotheses were not supported by the findings. No significant associations were exhibited for sleep patterns with pain, negative affect, or positive affect. However, positive associations between disease activity and sleep disturbance, as well as health-related quality of life and morningness were demonstrated. Moreover, it is encouraging that children and adolescents who are in disease remission are experiencing good quality sleep and few emotional problems. This reinforces the importance of psychologists supporting their physician colleagues in helping youth to manage their IBD and achieve remission status by screening and providing recommendations to promote adherence to treatment regimens and medical appointments (Hommel et al., 2013). It also is worth nothing that the current study had several methodological strengths. This study utilized a multi-method, multi-informant approach including use of objective sleep data, which is less susceptible to biases associated with subjective measurement. Use of such an approach lessens the probability of finding significant associations due to shared method variance. In addition, a prospective study design allows for investigation of temporal associations between study variables and directionality of these associations. To analyze these associations, multilevel modeling was utilized. This statistical approach allows for the examination of data at the within-person level (i.e., changes in an individual across time) and the between-persons level (i.e., differences between participants), as well as procedures for analyzing unequal amounts of data and missing data (Curran, Obeidat, \& Losardo, 2010). Moreover, because multilevel modeling draws its statistical power from the number of observations rather than the number of persons (Curran, Obeidat, \& Losardo, 2010; Schwartz \& Stone, 1998), use of relatively 
small sample sizes with a large number of observations, like the current study, can have sufficient statistical power to detect effects. However, it is critical to have diversity in terms of disease activity and pain severity when utilizing small sample size to ensure there is sufficient variability among these variables. Future research using longer assessment periods (e.g., three months) and more valid assessment approaches (e.g., EMA) may capture the waxing and waning course of IBD symptoms symptomatology (CCFA, 2014) and provide further insight on intra-individual variability in the association of pain or disease activity and sleep.

Because sleep disruption and circadian rhythm may be associated with gastrointestinal inflammation (Swanson, Burgess, \& Keskavazian, 2011) and inflammatory processes have been linked to sleep disturbance (Ranjbaran et al., 2007b), it is essential to investigate sleep within pediatric IBD. This may be especially important among youth with moderate to severe disease activity, who were not adequately represented in the current sample. It also is necessary to identify variables that are amendable to intervention (e.g., mood, pain) in efforts to promote sleep in this population. Future research should continue to assess sleep patterns using multiple subjective and objective methods, including polysomnography, and potentially associated factors (e.g., GIspecific anxiety, functional disability). Such research may provide insight on how to foster psychosocial functioning and optimal health outcomes among children and adolescents with IBD. 


\section{References}

Ali, T., Madhoun, M. F., Orr, W. C., \& Rubin, D. T. (2013). Assessment of the relationship between quality of sleep and disease activity in inflammatory bowel disease patients. Inflammatory Bowel Disease, 19, 2440-2443. doi: 10.1097/MIB.0b013e3182a0ea54

Ananthakrishnan, A. N., Long, M. D., Martin, C. F., Sandler, R. S., \& Kappelman M. D. (2013). Sleep disturbance and risk of active disease in patients with Crohn's disease and ulcerative colitis. Clinical Gastroenterology and Hepatology, 11, 965-971.

Aviel, Y. B., Stremler, R., Benseler, S. M., Cameron, B., Laxer, R. M., Ota, S., ... Brian M. Feldman, B. M. (2011). Sleep and fatigue and the relationship to pain, disease activity and quality of life in juvenile idiopathic arthritis and juvenile dermatomyositis. Rheumatology, 50, 2051-2060. doi: 10.1093/rheumatology/ker256

Banez, G. A. \& Cunningham, C. L. (2009). Abdominal pain-related gastrointestinal disorders: Irritable bowel syndrome and inflammatory bowel disease. In M. C. Roberts \& R. G. Steele (Eds.), Handbook of Pediatric Psychology (pp. 403-419). New York, NY: The Guilford Press.

Barlow, J. H. \& Ellard, D. R. (2006). The psychosocial well-being of children with chronic disease, their parents and siblings: An overview of the research evidence base. Child: Care, Health and Development, 32, 19-31.

Benchimol, E. I., Fortinsky, K. J., Gozdyra, P., Van den Heuvel, M., Van Limbergen, J., \& Griffiths, A. M. (2011). Epidemiology of pediatric inflammatory bowel disease: A systematic review of international trends. Inflammatory Bowel Disease, 17, 423-439. doi: 10.1002/ibd.21349 
Benhayon, D., Youk, A., McCarthy, F. N., Davis, S., Keljo, D. J., Bousvaros, A., ... Szigethy, E. M. (2013). Characterization of relations among sleep, inflammation, and psychiatric dysfunction in depressed youth with Crohn disease. Journal of Pediatric Gastroenterology \& Nutrition, 57, 335-342.

Bielefeldt, K., Davis, B., \& Binion, D. G. (2009). Pain and inflammatory bowel disease. Inflammatory Bowel Disease, 15, 778-788. doi:10.1002/ibd.20848

Bryant, P. A., Trinder, J., \& Curtis, N. (2004). Sick and tired: Does sleep have a vital role in the immune system. Nature Reviews Immunology, 4, 457-467.

Buchman, A. L. (2001). Side effects of corticosteroid therapy. Journal of Clinical Gastroenterology, 33, 289-294.

Burgess, H. J., Swanson, G. R., \& Keshavarzian, A. (2010). Endogenous melatonin profiles in asymptomatic inflammatory bowel disease. Scandinavian Journal of Gastroenterology, 45, 759-761. doi: 10.3109/00365521003749818

Centers for Disease Control and Prevention (CDC). (2012, November 1). Health-related quality of life. Retrieved from http://www.cdc.gov/hrqol/

Centers for Disease Control and Prevention (CDC). (2014, January 14). Inflammatory Bowel Disease. Retrieved from http://www.cdc.gov/ibd/index.htm

Chervin, R. D., Hedger, K. Dillon, J. E., \& Pituch, K. J. (2000). Pediatric sleep questionnaire (PSQ): Validity and reliability of scales for sleep-disordered breathing, snoring, sleepiness, and behavioral problems. Sleep Medicine, 1, 21-32. doi: 10.1016/S1389-9457(99)00009-X

Chorney, D. B., Detweiler, M. F., Morris, T. L., \& Kuhn, B. R. (2008). The interplay of sleep disturbance, anxiety, and depression in children. Journal of Pediatric Psychology, 33, 339348. doi: 10.1093/jpepsy/jsm105 
Crohn's \& Colitis Foundation of America (CCFA). (2014). What are Crohn's and Colitis?

Retrieved from http://www.ccfa.org/what-are-crohns-and-colitis/

Curran, P. J., Obeidat, K., \& Losardo, D. (2010). Twelve frequently asked questions about growth curve modeling. Journal of Cognition and Development, 11, 121-136.

doi: $10.1080 / 15248371003699969$

Eiser, C. \& Morse, R. (2001) Can parents rate their child's health-related quality of life? Results of a systematic review. Quality of Life Research, 10, 347-357.

Fallone, G., Owens, J. A., \& Deane, J. (2002). Sleepiness in children and adolescents: Clinical implications. Sleep Medicine Reviews, 6, 287-306.

Fredericks, E. M., Dore-Stites, D., Calderon, S. Y., Well, A., Eder, S. J., Magee, J. C., \& Lopez, M. J. (2012). Relationship between sleep problems and health-related quality of life among pediatric liver transplant recipients. Liver Transplantation, 18, 707-715.

doi: 10.1002/lt.23415

Gallo, J., Grant, A., Otley, A. R., Orsi, M., MacIntyre, B., Gauvry, S., \& Lifschitz, C. (2014). Do parents and children agree? Quality-of-life assessment of children with inflammatory bowel disease and their parents. Journal of Pediatric Gastroenterology \& Nutrition, 58, 481-485. doi: 10.1097/MPG.0000000000000236

Gil, K. M., Carson, J. W., Porter, L. S., Ready, J., Valrie, C., Redding-Lallinger, R., \& Daeschner, C. (2003). Daily stress and mood and their association with pain, health-care use, and school activity in adolescents with sickle cell disease. Journal of Pediatric Psychology, 28, 363-373. doi: 10.1093/jpepsy/jsg026 
Graff, L. A., Clara, I., Walker, J. R., Lix, L., Carr, R., Miller, N., ... Bernstein, C. N. (2013). Changes in fatigue over 2 years are associated with activity of inflammatory bowel disease and psychological factors. Clinical Gastroenterology and Hepatology, 11, 1140-1146.

Graff, L. A., Vincent, N., Walker, J. R., Clara, I., Carr, R., Ediger, J., ... Bernstein, C. N. (2011). A population-based study of fatigue and sleep difficulties in inflammatory bowel disease. Inflammatory Bowel Disease, 17, 1882-1889. doi: 10.1002/ibd.21580

Greenley, R, N., Hommel, K. A., Nebel, J., Raboin, T., Li, S., Simpson, P., \& Mackner, L. (2010). A meta-analytic review of the psychosocial adjustment of youth with inflammatory bowel disease. Journal of Pediatric Psychology, 35, 857-869. doi: 10.1093/jpepsy/jsp120

Haim, A., Pillaer, G., Pecht, A., Lerner, A., Tov, N., Jaffe, M., \& Hardoff, D. (2004). Sleep patterns in children and adolescents with functional recurrent abdominal pain: Objective versus subjective assessment. Acta Paediatrica, 93, 677-680.

doi: $10.1080 / 08035250310007466$

Hommel, K. A., Greenley, R. N., Maddux, M. H., Gray, W. N., \& Mackner, L. M. (2013). Selfmanagement in pediatric inflammatory bowel disease: A clinical report of the North American Society for Pediatric Gastroenterology, Hepatology, and Nutrition. Journal of Pediatric Gastroenterology \& Nutrition, 57, 250-257.

doi: 10.1097/MPG.0b013e3182999b21

Hoogerwerf, W. A. (2009). Role of biological rhythms in gastrointestinal health and disease. Reviews in Endocrine and Metabolic Disorders, 10, 293-300.

doi: 10.1007/s11154-009-9119-3. 
Huntley, E. D., Campo, J. V., Dahl, R. E., \& Lewin, D. S. (2007). Sleep characteristics of youth with functional abdominal pain and a healthy comparison group. Journal of Pediatric Psychology, 32, 938-949. doi: 10.1093/jpepsy/jsm032

Huscher, D., Thiele, K., Gromnica-Ihle, E., Hein, G., Demary, W., Dreher, R., ... Buttgereit, F. (2009). Dose-related patterns of glucocorticoid-induced side effects. Annals of Rheumatic Diseases, 68, 1119-1124 doi: 10.1136/ard.2008.092163

Hyams, J. S., Ferry, G. D., Mandel, F. S., Gryboski, J. D., Kibort, P. M., Kirschner, B. S., ... Lesser, M. L. (1991). Development and validation of a Pediatric Crohn's Disease Activity Index. Journal of Pediatric Gastroenterology \& Nutrition, 12, 439-447.

Hyams, J., Markowitz, J., Otley, A., Rosh, J., Mack, D., Bousvaros, A., ... Griffiths, A. (2005). Evaluation of the Pediatric Crohn Disease Activity Index: A prospective multicenter experience. Journal of Pediatric Gastroenterology \& Nutrition, 41, 416-421.

Hyde, M., O’Driscoll, D.M., Binette, S., Galang, C., Tan, S.K., Verginis, N., ... Horne, R. S. C. (2007). Validation of actigraphy for determining sleep and wake in children with sleep disordered breathing. Journal of Sleep Research, 16, 213-216.

doi: $10.1111 / \mathrm{j} .1365-2869.2007 .00588 . \mathrm{x}$

Jahng, S., Wood, P.K., Trull, T.J. (2008). Analysis of affective instability in ecological momentary assessment: Indices using successive difference and group comparison via multilevel modeling. Psychological Methods, 13, 354-375. doi: 10.1037/a0014173

Keefer, L., Stepanski, E. J., Ranjbaran, Z., Benson, L. M., \& Keshavarzian, A. (2006). An initial report of sleep disturbance in inactive inflammatory bowel disease. Journal of Clinical Sleep Medicine, 2, 409-416. 
Kim, S. C. \& Ferry, G. D. (2004). Inflammatory bowel disease in pediatric and adolescent patients: Clinical, therapeutic, and psychosocial considerations. Gastroenterology, 126, 1550-1560. doi: $10.1053 /$ j.gastro.2004.03.022

Labus, J. S., Bolus, R., Chang, L., Wiklund, I., Naesdal, J., Mayer, E. A., \& Naliboff, B. D. (2004). The Visceral Sensitivity Index: Development and validation of a gastrointestinal symptomspecific anxiety scale, Alimentary Pharmacology \& Therapeutics, 20, 89-97. doi: 10.1111/j.1365-2036.2004.02007.x

Laurent, J., Catanzaro, S. J., Joiner Jr., T. E., Rudolph, K. D., Potter, K. I., Lambert, S., ,.. Gathright, T. (1999). A measure of positive and negative affect for children: Scale development and preliminary validation. Psychological Assessment, 13, 326-338

Lewandowski, A. S., Ward, T. M., \& Palermo, T. M. (2011). Sleep problems in children and adolescents with common medical conditions. Pediatric Clinics of North America, 58, 699713. doi: $10.1016 /$ j.pel.2011.03.012

Lewin, D. S. \& Dahl, R. E. (1999). The importance of sleep in the management of pediatric pain. Journal of Developmental and Behavioral Pediatrics, 20, 244-252.

Mackner, L. M., Greenley, R. N., Szigethy, E., Herzer, M., Deer, K., \& Hommel, K. A. (2013). Psychosocial issues in pediatric inflammatory bowel disease: Report of the North American Society for Pediatric Gastroenterology, Hepatology, and Nutrition. Journal of Pediatric Gastroenterology \& Nutrition, 56, 449-458. doi: 10.1097/MPG.0b013e3182841263.

Marcus, S. B., Strople, J. A., Neighbors, K., Weissberg-Benchell, J., Nelson, S. P., Limbers, C., ... Alonso, E. M. (2009). Fatigue and health-related quality of life in pediatric inflammatory bowel disease. Clinical Gastroenterology and Hepatology, 7, 544-561.

doi: 10.1016/j.cgh.2009.01.022 
Meltzer, L. J., Logan, D. E., \& Mindell, J. A. (2003). Sleep patterns in female adolescents with chronic musculoskeletal pain. Behavioral Sleep Medicine, 3, 193-208.

Meltzer, L. J. \& Mindell, J. A. (2009). Pediatric sleep. In M. C. Roberts \& R. G. Steele (Eds.), Handbook of Pediatric Psychology (pp. 491-507). New York, NY: The Guilford Press.

Meltzer, L. J., Montgomery-Downs, H. E., Insana, S. P. \& Walsh, C. M. (2012). Use of actigraphy for assessment in pediatric sleep research. Sleep Medicine Reviews, 16, 463-475. doi: 10.1016/j.smrv.2011.10.002

Meltzer, L. J., Walsh, C. M., Traylor, J., \& Westin, A. M. L. (2012). Direct comparison of two new actigraphs and polysomnography in children and adolescents. SLEEP, 35, 159-166. doi: $10.5665 /$ sleep. 1608

Nachmias, V., Sheinberg, A., Weiss, B., Fradkin, A., \& Bujanover, Y. (2006). Sleep disturbances among young patients with IBD in Israel. Journal of Pediatric Gastroenterology \& Nutrition, 43(suppl 2), S48.

O’Driscoll, D. M., Foster, A. M., Davey, M. J., Nixon, G. M., \& Horne R. S. (2009). Can actigraphy measure sleep fragmentation in children? Archives of Disease in Children, 95, 1031-1033 doi: 10.1136/adc.2009.166561

Ohayon, M. M., Carskadon, M. A., Guilleminault, C., \& Vitiello, M. V. (2004). Meta-analysis of quantitative sleep parameters from childhood to old age in healthy individuals: developing normative sleep values across the human lifespan. Sleep, 27, 1255-1273.

Otley, A., Smith, C., Nicholas, D., Munk, M., Avolio, J., Sherman, P. M., \& Griffiths, A. M. (2002). The IMPACT questionnaire: A valid measure of health-related quality of life in pediatric inflammatory bowel disease. Journal of Pediatric Gastroenterology \& Nutrition. $35,557-563$. 
Otley, A. R., Xu, S., Yan, S., Olson, A., Liu, G., Griffiths, A. M., \& the REACH Study Group. (2006). IMPACT-III is a valid, reliable and responsive measure of health-related quality of life in pediatric Crohn's Disease. Journal of Pediatric Gastroenterology \& Nutrition, 43, S49.

Owens, J. A., Spirito, A., \& McGuinn, M. (2000). The Children's Sleep Habits Questionnaire (CSHQ): Psychometric properties of a survey instrument for school-age children. SLEEP, $23,1-9$.

Owens, J. A., Jones, C., \& Nash, R. (2011). Caregivers' knowledge, behavior, and attitudes regarding healthy sleep in young children. Journal of Clinical Sleep Medicine, 7, 345-50. doi: 10.5664/JCSM.1186

Palermo, T. M., Long, A. C., Lewandowski, A. S., Drotar, D., Quittner, A. L., \& Walker, L. S. (2008). Evidence-based assessment of health-related quality of life and functional impairment in pediatric psychology. Journal of Pediatric Psychology, 33, 983-996. doi: 10.1093/jpepsy/jsn038

Palermo, T. M. \& Kiska, R. (2005). Subjective sleep disturbances in adolescents with chronic pain: Relationship to daily functioning and quality of life. The Journal of Pain, 6, 201-207. doi: 10.1016/j.jpain.2004.12.005

Palermo, T. M., Toliver-Sokol, M., Fonareva, I., \& Koh, J. L. (2007). Objective and subjective assessment of sleep in adolescents with chronic pain compared to healthy adolescents. Clinical Journal of Pain, 23, 812-820. doi: 10.1097/AJP.0b013e318156ca63

Palermo, T. M., Wilson, A. C., Lewandowski, A. S., Toliver-Sokol, M., \& Murray, C. B. (2011). Behavioral and psychosocial factors associated with insomnia in adolescents with chronic pain. Pain, 152, 89-94. doi: 10.1016/j.pain.2010.09.035 
Pirinen, T., Kolho, K. L., Simola, P., Ashorn, M., \& Aronen, E. T. (2010). Parent and self-report of sleep-problems and daytime tiredness among adolescents with inflammatory bowel disease and their population-based controls. SLEEP, 33, 1487-1493.

Randler, C. (2011). Association between morningness-eveningness and mental and physical health in adolescents. Psychology, Health, \& Medicine, 16, 29-38.

doi: $10.1080 / 13548506.2010 .521564$

Ranjbaran, Z, Keefer, L., Farhadi, A., Stepanski, E., Sedghi, S., \& Keshavarzian, A. (2007). Impact of sleep disturbances in inflammatory bowel disease. Journal of Gastroenterology and Hepatology, 22, 1748-1753.

Ranjbaran, Z., Keefer, L., Stepanski, E., Farhadi, A., \& Keshavarzian, A. (2007b). The relevance of sleep abnormalities to chronic inflammatory conditions. Inflammation Research, 56, 5157. doi: 10.1007/s00011-006-6067-1

Schwartz, J. E. \& Stone, A. A. (1998). Strategies for analyzing ecological momentary assessment data. Health Psychology, 17, 6-16.

Shiffman, S., Stone, A.A., \& Hufford, M.R. (2008). Ecological momentary assessment. Annual Review of Clinical Psychology, 4, 1-32. doi: 10.1146/annurev.clinpsy.3.022806.091415

Swanson, G. R., Burgess, H. J., \& Keshavarzian, A. (2011). Sleep disturbances and inflammatory bowel disease: A potential trigger for disease flare? Expert Review of Clinical Immunology, 7, 29-36. doi: 10.1586/eci.10.83

Turner, D., Otley, A.R., Mack, D., Hyams, J., de Bruijne, J., Uusoue, K, ... Griffiths, A. M. (2007). Development, validation, and evaluation of a Pediatric Ulcerative Colitis Activity Index: A prospective multicenter study. Gastroenterology, 133, 423-432.

doi: 10.1053/j.gastro.2007.05.029 
Valrie, C. R., Gil, K. M., Redding-Lallinger, R. \& Daeschner, C. (2007). Brief report: Sleep in children with sickle cell disease: An analysis of daily diaries utilizing multilevel models. Journal of Pediatric Psychology, 32, 857-861. doi: 10.1093/jpepsy/jsm016

Wolfson, A. R. \& Carskadon, M. A. (2003). Understanding adolescents'sleep patterns and school performance: A critical appraisal. Sleep Medicine Review, 7, 491-506.

Wolfson, A. R., Carskadon, M. A., Acebo, C., Seifer, R., Fallone, G., Labyak, S. E., \& Martin, J. L. (2003). Evidence for the validity of a Sleep Habits Survey for adolescents. SLEEP, 26, 213-216.

Zempsky, W. T., Palermo, T. M., Corsi, J. M., Lewandowski, A. S., Zhou, C., \& Casella, J. F. (2013). Daily changes in pain, mood and physical function in youth hospitalized for sickle cell disease pain. Pain Research \& Management, 18, 33-38. PMCID: PMC3665435

Zimmerman, J. (2003). Extraintestinal symptoms in irritable bowel syndrome and inflammatory bowel diseases: nature, severity, and relationship to gastrointestinal symptoms. Digestive Diseases and Sciences, 48, 743-749. 
Table 1

Study Timeline

\begin{tabular}{|c|c|c|c|}
\hline Time & Patient measures & Parent measures & Physician measures \\
\hline $\begin{array}{l}\text { Time } 1 \\
\text { (Day 1) }\end{array}$ & $\begin{array}{l}\text { 1) Pain \& Sleep Diary } \\
\text { 2) Positive and Negative } \\
\text { Affect Schedule for } \\
\text { Children } \\
\text { 3) Sleep Habits Survey }\end{array}$ & $\begin{array}{l}\text { 1) Family Information } \\
\text { Form } \\
\text { 2) Children's Sleep Habits } \\
\text { Questionnaire }\end{array}$ & $\begin{array}{l}\text { Pediatric Crohn's } \\
\text { Disease Activity Index } \\
\text { or Pediatric Ulcerative } \\
\text { Colitis Activity Index } \\
\text { (depending on patient } \\
\text { diagnosis) }\end{array}$ \\
\hline $\begin{array}{l}\text { Days } 2- \\
13^{\mathrm{a}}\end{array}$ & $\begin{array}{l}\text { 1) Pain \& Sleep Diary } \\
\text { 2) Positive and Negative } \\
\text { Affect Schedule for } \\
\text { Children } \\
\text { 3) Actigraphy }\end{array}$ & $\mathrm{N} / \mathrm{A}$ & $\mathrm{N} / \mathrm{A}$ \\
\hline $\begin{array}{l}\text { Time } 2 \\
\text { (Day } 14 \text { ) }\end{array}$ & $\begin{array}{l}\text { 1) Pain \& Sleep Diary } \\
\text { 2) Positive and Negative } \\
\text { Affect Schedule for } \\
\text { Children } \\
\text { 3) Actigraphy } \\
\text { 4) IMPACT-III }\end{array}$ & 1) $I M P A C T-I I I$ & N/A \\
\hline
\end{tabular}

${ }^{\mathrm{a}}$ Measures completed daily during this time period 
Table 2

Schedule of Participant Remuneration

\begin{tabular}{lll}
\hline \multicolumn{1}{c}{ Time } & \multicolumn{1}{c}{ Patient remuneration } & \multicolumn{1}{c}{ Parent remuneration } \\
\hline Time 1 (Day 1) measures & $\$ 10$ gift card & \$10 gift card \\
Days 2 - 13 measures & $\begin{array}{l}\text { \$2.50 per completed diary } \\
\text { day }(\$ 30 \text { for 12 days) } \\
\$ 5 \text { if no missing data }\end{array}$ & N/A \\
& \$10 gift card & \$10 gift card \\
Time 2 (Day 14) measures & Lottery ticket for 1 of \$50 & N/A \\
\hline
\end{tabular}


Table 3

Sample Demographics

\begin{tabular}{|c|c|c|c|c|}
\hline Variables $(\mathrm{N}=\mathbf{2 5})$ & n (\%) & Mean & SD & Range \\
\hline Patient age (in years) & & 14.25 & 2.42 & $10-18$ \\
\hline \multicolumn{5}{|l|}{ Patient gender } \\
\hline Male & $14(56 \%)$ & & & \\
\hline Female & $11(44 \%)$ & & & \\
\hline \multicolumn{5}{|l|}{ Patient race } \\
\hline White & $22(88 \%)$ & & & \\
\hline Mixed race & $3(12 \%)$ & & & \\
\hline \multicolumn{5}{|l|}{ Diagnosis } \\
\hline Crohn's disease & $20(80 \%)$ & & & \\
\hline ulcerative colitis & $5(20 \%)$ & & & \\
\hline$P C D A I$ total score & & 7.5 & 7.12 & $0-30$ \\
\hline Inactive disease & $17(68 \%)$ & & & \\
\hline Mild disease & $3(12 \%)$ & & & \\
\hline Moderate to severe disease & $0(0 \%)$ & & & \\
\hline PUCAI total score & & 7 & 9.75 & $0-20$ \\
\hline Disease remission & $3(12 \%)$ & & & \\
\hline Mild disease & $2(8 \%)$ & & & \\
\hline Moderate to severe disease & $0(0 \%)$ & & & \\
\hline \multicolumn{5}{|c|}{ Number of symptom flares in past year } \\
\hline 0 flares & $11(44 \%)$ & & & \\
\hline 1 flare & $8(32 \%)$ & & & \\
\hline 2 flares & $5(20 \%)$ & & & \\
\hline 3 flares & $1(4 \%)$ & & & \\
\hline \multicolumn{5}{|l|}{ Primary caregiver relationship } \\
\hline Mother & $22(88 \%)$ & & & \\
\hline Father & $1(4 \%)$ & & & \\
\hline Grandmother2 & $1(4 \%)$ & & & \\
\hline Legal Guardian & $1(4 \%)$ & & & \\
\hline Primary caregiver age (in years) & & 43.36 & 6.58 & $34-57$ \\
\hline
\end{tabular}


Family structure $^{\mathrm{a}}$

Intact

Blended

Single

Missing

Mother highest education level

Graduated from high school

Some college or specialized training

Bachelor's degree

Master's or doctoral degree

Father highest education level

$7^{\text {th }}, 8^{\text {th }}$, or $9^{\text {th }}$ grade

Graduated from high school

Some college or specialized training

Bachelor's degree

Master's or doctoral degree

Missing

Total family income

Less than $\$ 10,000$

$\$ 10,000-14,999$

$\$ 15,000-24,999$

$\$ 25,000-34,999$

$\$ 35,000-49,999$

$\$ 50,000-74,999$

$\$ 75,000-99,999$

$\$ 100,000$ - 149,999

$\$ 150,000$ or more
$17(68 \%)$

$4(16 \%)$

$3(12 \%)$

$1(4 \%)$

$7(28 \%)$

$8(32 \%)$

$9(36 \%)$

$1(4 \%)$

$1(4 \%)$

$8(32 \%)$

$8(32 \%)$

$4(16 \%)$

$2(8 \%)$

$2(8 \%)$

$1(4 \%)$

$2(8 \%)$

$4(16 \%)$

$2(8 \%)$

$3(12 \%)$

$3(12 \%)$

$5(20 \%)$

$3(12 \%)$

$2(8 \%)$

\footnotetext{
${ }^{\mathrm{a}}$ Intact $=$ married to other biological parent; blended $=$ remarried to step-parent; single $=$ never been married, divorced, widowed, or living with boyfriend/girlfriend
} 
Table 4

Descriptives of study variables

\begin{tabular}{|c|c|c|c|}
\hline $\begin{array}{c}\text { Variables } \\
(\mathrm{N}=\mathbf{2 5}, \text { except where noted }) \\
\end{array}$ & Mean & SD & $\begin{array}{c}\text { Possible Range } \\
\text { (except where noted) }\end{array}$ \\
\hline SHS sleepiness scale ${ }^{\mathrm{a}}$ & 13.13 & 2.79 & $15-75$ \\
\hline$S H S$ sleep/wake problems behavior scale ${ }^{a}$ & 17.96 & 6.90 & $10-40$ \\
\hline $\begin{array}{l}\text { SHS Superscience } \\
\text { morningness/eveningness scale }\end{array}$ & 28.08 & 4.46 & $10-43$ \\
\hline$S H S$ weekday sleep duration (in minutes) ${ }^{\mathrm{a}}$ & 447.04 & 70.90 & $312-580^{\mathrm{e}}$ \\
\hline$S H S$ weekend sleep duration (in minutes) ${ }^{\mathrm{a}}$ & 572.78 & 75.58 & $480-737^{\mathrm{e}}$ \\
\hline$C S H Q$ total sleep disturbance score ${ }^{\mathrm{b}}$ & 44 & 4.93 & $33-99$ \\
\hline$C S H Q$ bedtime resistance ${ }^{b}$ & 7.39 & 2.55 & $6-18$ \\
\hline$C S H Q$ sleep onset delay ${ }^{\mathrm{b}}$ & 1.52 & 0.73 & $1-3$ \\
\hline CSHQ sleep duration ${ }^{\mathrm{b}}$ & 4.83 & 1.95 & $3-9$ \\
\hline CSHQ sleep anxiety ${ }^{\mathrm{b}}$ & 4.91 & 2.23 & $4-12$ \\
\hline$C S H Q$ night wakings ${ }^{\text {b }}$ & 4.13 & 1.10 & $3-9$ \\
\hline$C S H Q$ parasomnias $^{\mathrm{b}}$ & 7.70 & 1.52 & $7-21$ \\
\hline$C S H Q$ sleep disordered breathing ${ }^{\mathrm{b}}$ & 3.09 & 0.60 & $3-9$ \\
\hline$C S H Q$ daytime sleepiness ${ }^{\mathrm{b}}$ & 13.04 & 1.94 & $8-24$ \\
\hline$C S H Q$ sleep duration (in minutes) ${ }^{\mathrm{c}}$ & 486.82 & 50.96 & $420-600^{e}$ \\
\hline$C S H Q$ night waking duration (in minutes) ${ }^{\mathrm{d}}$ & 11.37 & 15.74 & $0-60^{\mathrm{e}}$ \\
\hline Actigraphy total sleep time (in minutes) & 409.81 & 56.91 & $326.18-514^{\mathrm{e}}$ \\
\hline Actigraphy sleep onset latency (in minutes) & 5.65 & 3.72 & $0-14.73^{\mathrm{e}}$ \\
\hline $\begin{array}{l}\text { Actigraphy wake after sleep onset (in } \\
\text { minutes) }\end{array}$ & 54.36 & 23.35 & $9-121.15^{\mathrm{e}}$ \\
\hline
\end{tabular}


Actigraphy sleep efficiency

PANAS-C negative affect

$P A N A S-C$ positive affect

Average self-report abdominal pain

IMPACT - III youth total score

IMPACT - III parent total score

${ }^{\mathrm{a}} n=24$

${ }^{\mathrm{b}} n=23$

${ }^{\mathrm{c}} n=22$

${ }^{\mathrm{d}} n=19$

${ }^{\mathrm{e}}$ current sample range
$85.01 \% \quad 4.46 \% \quad 73.93-93.34 \%^{\mathrm{e}}$

$\begin{array}{lll}19.04 & 4.21 & 15-75\end{array}$

43.81

12.86

$15-75$

0.93

1.24

$0-10$

76.37

11.93

$0-100$

74.71

13.26

$0-100$ 
Table 5

Descriptives of Parental Beliefs and Knowledge Questions

\begin{tabular}{|c|c|}
\hline Questions $(\mathrm{N}=25)$ & n (\%) \\
\hline $\begin{array}{l}\text { I believe my child gets enough sleep. } \\
\text { Agree } \\
\text { Disagree } \\
\text { Neither agree or disagree }\end{array}$ & $\begin{array}{r}11(44 \%) \\
9(36 \%) \\
5(20 \%)\end{array}$ \\
\hline $\begin{array}{l}\text { I believe my child has healthy sleep habits. } \\
\text { Agree } \\
\text { Disagree } \\
\text { Neither agree or disagree }\end{array}$ & $\begin{array}{r}9(36 \%) \\
6(24 \%) \\
10(40 \%)\end{array}$ \\
\hline $\begin{array}{l}\text { Children who don't get enough sleep are more likely to be } \\
\text { underweight than overweight. } \\
\text { True } \\
\text { False } \\
\text { Don't know }\end{array}$ & $\begin{array}{r}5(20 \%) \\
11(44 \%) \\
9(36 \%)\end{array}$ \\
\hline $\begin{array}{l}\text { Snoring in a child indicates that he or she is sleeping well. } \\
\text { True } \\
\text { False } \\
\text { Don't know }\end{array}$ & $\begin{array}{c}1(4 \%) \\
24(96 \%) \\
0(0 \%)\end{array}$ \\
\hline $\begin{array}{l}\text { Being either under or over-active can both be warning signs that } \\
\text { a child is not getting enough sleep. } \\
\text { True } \\
\text { False } \\
\text { Don't know }\end{array}$ & $\begin{array}{r}15(60 \%) \\
4(16 \%) \\
6(24 \%)\end{array}$ \\
\hline $\begin{array}{l}\text { Watching TV in their bedroom makes it more difficult for } \\
\text { children to fall asleep. } \\
\text { True } \\
\text { False } \\
\text { Don't know }\end{array}$ & $\begin{aligned} 17 & (68 \%) \\
4 & (16 \%) \\
4 & (16 \%)\end{aligned}$ \\
\hline $\begin{array}{l}\text { Children should have the same bedtime and wake time on } \\
\text { weekdays and weekends. } \\
\text { True } \\
\text { False } \\
\text { Don't know }\end{array}$ & $\begin{array}{r}16(64 \%) \\
7(28 \%) \\
2(8 \%)\end{array}$ \\
\hline $\begin{array}{l}\text { Children only need a bedtime routine if they are having trouble } \\
\text { falling asleep. } \\
\text { True } \\
\text { False } \\
\text { Don't know }\end{array}$ & $\begin{array}{l}25(100 \%) \\
\quad 0(0 \%) \\
0(0 \%)\end{array}$ \\
\hline
\end{tabular}


Well-rested children don't need an alarm clock to wake up in the morning.

True

False

$3(12 \%)$

$16(64 \%)$

Don't know

$6(24 \%)$

The average preschooler (3-5 years) needs about 10 hours of sleep/24hrs.

True

$19(76 \%)$

False

$3(12 \%)$

Don't know

$3(12 \%)$

Being overweight can increase a child's risk of sleep problems.

True

False

$19(76 \%)$

$2(8 \%)$

Don't know

$4(16 \%)$

The average school-aged child (6-12 years) needs about 8 hours of sleep.

True

$17(68 \%)$

False

$6(24 \%)$

Don't know 
Table 6

Sleep Variables compared to Healthy Samples

\begin{tabular}{|c|c|c|c|c|c|}
\hline Variable & $\begin{array}{c}\text { Current } \\
\text { Study } \\
M(S D)\end{array}$ & $\begin{array}{c}\text { Healthy } \\
\text { Comparison } \\
M(S D)\end{array}$ & $t$ & $p$ & $d f$ \\
\hline $\begin{array}{l}C S H Q \text { bedtime }^{\text {a }} \\
\text { resistance }^{\mathrm{a}}\end{array}$ & $7.39(2.55)$ & $7.06(1.89)$ & .62 & $n s$ & 22 \\
\hline$C S H Q$ sleep onset delay ${ }^{a}$ & $1.52(0.73)$ & $1.25(0.53)$ & 1.78 & $n s$ & 22 \\
\hline$C S H Q$ sleep duration ${ }^{\mathrm{a}}$ & $4.83(1.95)$ & $3.41(0.93)$ & 3.49 & .002 & 22 \\
\hline$C S H Q$ sleep anxiety ${ }^{\mathrm{a}}$ & $4.91(2.23)$ & $4.89(1.45)$ & .05 & $n s$ & 22 \\
\hline$C S H Q$ night wakings ${ }^{\mathrm{a}}$ & $4.13(1.10)$ & $3.51(0.89)$ & 2.71 & .013 & 22 \\
\hline$C S H Q$ parasomnias $^{\mathrm{a}}$ & $7.70(1.52)$ & $8.11(1.25)$ & -1.31 & $n s$ & 22 \\
\hline $\begin{array}{l}C S H Q \text { sleep disordered } \\
\text { breathing }^{\text {a }}\end{array}$ & $3.09(0.60)$ & $3.24(0.63)$ & -1.23 & $n s$ & 22 \\
\hline $\begin{array}{l}C S H Q \text { daytime } \\
\text { sleepiness }^{\mathrm{a}}\end{array}$ & $13.04(1.94)$ & $9.64(2.80)$ & 8.41 & .001 & 22 \\
\hline$S H S$ sleepiness ${ }^{\mathrm{b}}$ & $13.13(2.79)$ & $14.03(3.51)$ & -1.59 & $n s$ & 23 \\
\hline $\begin{array}{l}\text { SHS sleep-wake } \\
\text { problems }^{\text {b }}\end{array}$ & $17.96(6.90)$ & $18.48(6.63)$ & -.37 & $n s$ & 23 \\
\hline $\begin{array}{l}\text { Actigraphy total sleep } \\
\text { time (in minutes) }{ }^{c}\end{array}$ & $\begin{array}{l}409.81 \\
(56.91)\end{array}$ & $434.10(60.90)$ & -2.13 & .043 & 24 \\
\hline $\begin{array}{l}\text { Actigraphy wake after } \\
\text { sleep onset (in minutes) }\end{array}$ & $\begin{array}{c}54.36 \\
(23.35)\end{array}$ & $69.20(40.70)$ & -3.18 & .004 & 24 \\
\hline $\begin{array}{l}\text { Actigraphy sleep } \\
\text { efficiency }\end{array}$ & $\begin{array}{l}85.01 \% \\
(4.46 \%)\end{array}$ & $\begin{array}{l}82.30 \% \\
(10.30 \%)\end{array}$ & 3.04 & .006 & 24 \\
\hline
\end{tabular}

Note: $n s=$ non-significant

${ }^{a}$ Healthy comparison data taken from Owens, Spirito, \& McGuinn, 2000

${ }^{\mathrm{b}}$ Healthy comparison data taken from Wolfson \& Carskadon, 2003

${ }^{\mathrm{c}}$ Healthy comparison data taken from Meltzer, Walsh, Traylor, \& Westin, 2012 
Table 7

Correlations among Subjective Sleep Variables, Disease Activity, HRQOL, \& Patient Age

\begin{tabular}{|c|c|c|c|c|}
\hline Variable & $\begin{array}{c}I M P A C T-I I I \\
\text { youth }^{\mathrm{a}}\end{array}$ & $\begin{array}{c}I M P A C T-I I I \\
\text { parent }^{\mathrm{a}}\end{array}$ & $\begin{array}{l}\text { Disease } \\
\text { Activity }^{b}\end{array}$ & Patient age $^{\mathrm{a}}$ \\
\hline $\begin{array}{l}\text { CSHQ total sleep } \\
\text { disturbance }\end{array}$ & -.06 & -.11 & .21 & -.15 \\
\hline CSHQ bedtime resistance & -.10 & .05 & -.19 & .06 \\
\hline$C S H Q$ sleep onset delay & -.21 & -.15 & .22 & .02 \\
\hline CSHQ sleep duration & -.15 & -.28 & .22 & -.02 \\
\hline CSHQ sleep anxiety & -.17 & -.20 & -.02 & .21 \\
\hline CSHQ night wakings & -.24 & -.35 & .15 & $<.01$ \\
\hline$C S H Q$ parasomnias & .06 & .12 & .23 & -.21 \\
\hline $\begin{array}{l}C S H Q \text { sleep disordered } \\
\text { breathing }\end{array}$ & -.12 & -.16 & .12 & .15 \\
\hline CSHQ daytime sleepiness & -.04 & .10 & -.26 & -.08 \\
\hline SHS sleepiness & -.38 & -.34 & .17 & .31 \\
\hline$S H S$ sleep-wake problems & -.14 & -.02 & -.03 & .12 \\
\hline $\begin{array}{l}\text { SHS morningness- } \\
\text { eveningness }\end{array}$ & $.49 *$ & .31 & -.13 & -.20 \\
\hline Note: $* p<.05, * * p<.01$ & & & & \\
\hline
\end{tabular}


Table 8

Correlations among Objective Sleep Variables, Disease Activity, HRQOL, \& Patient Age

\begin{tabular}{lcccc}
\hline Variable & $\begin{array}{c}I M P A C T-I I I \\
\text { youth }^{\mathrm{a}}\end{array}$ & $\begin{array}{c}I M P A C T-I I I \\
\text { parent }^{\mathrm{a}}\end{array}$ & $\begin{array}{c}\text { Disease } \\
\text { Activity }^{\mathrm{b}}\end{array}$ & Patient age $^{\mathrm{a}}$ \\
\hline $\begin{array}{l}\text { Actigraphy total sleep } \\
\text { time }\end{array}$ & $-.30^{\mathrm{c}}$ & $-.10^{\mathrm{c}}$ & $.19^{\mathrm{c}}$ & $-.50^{*}$ \\
$\begin{array}{l}\text { Actigraphy sleep onset } \\
\text { latency }\end{array}$ & .01 & $<-.01$ & .33 & -.04 \\
$\begin{array}{l}\text { Actigraphy wake after } \\
\text { sleep onset }\end{array}$ & .05 & .02 & .10 & -.09 \\
$\begin{array}{l}\text { Actigraphy sleep } \\
\text { efficiency }\end{array}$ & -.03 & -.06 & -.07 & -.19 \\
$\begin{array}{l}\text { Actigraphy total sleep } \\
\text { time instability }\end{array}$ & -.08 & .01 & .17 & .08 \\
$\begin{array}{l}\text { Actigraphy sleep onset } \\
\text { latency instability }\end{array}$ & .15 & .16 & .15 & -.16 \\
$\begin{array}{l}\text { Actigraphy wake after } \\
\text { sleep onset instability }\end{array}$ & -.01 & -.01 & $.58^{* *}$ & $<-.01$ \\
$\begin{array}{l}\text { Actigraphy sleep } \\
\text { efficiency instability }\end{array}$ & -.02 & .13 & .17 & .07 \\
\hline
\end{tabular}

Note: $* p<.05, * * p<.01$

${ }^{\mathrm{a}}$ Pearson correlation coefficients except where noted

${ }^{\mathrm{b}}$ Spearman rank correlation coefficients except where noted

${ }^{\mathrm{c}}$ Partial correlation coefficients controlling for patient age 
Table 9

Multilevel Models of Abdominal Pain Predicting Sleep Variables

Model A: Sleep onset latency

\begin{tabular}{lccc}
\hline Fixed effects & $B$ & $S E$ & $p$ \\
\hline Disease activity - inactive & -2.81 & 5.04 & $n s$ \\
Patient age & -.10 & .33 & $n s$ \\
Mean pain & -.30 & .67 & $n s$ \\
Person-centered pain & 2.78 & 1.32 & $n s$ \\
\hline Random effects & & 4.72 & $n s$ \\
\hline Intercept & 3.09 & 13.97 & $n s$ \\
Person-centered pain & 12.79 & $S E$ & $p$ \\
\hline & Model B: Sleep efficiency & \\
\hline Fixed effects & $B$ & 2.38 & $n s$ \\
\hline Disease activity - inactive & -.24 & .40 & $n s$ \\
Patient age & -.37 & .78 & $n s$ \\
Mean pain & .37 & .39 & $n s$ \\
Person-centered pain & -.21 & 6.75 & .006 \\
\hline Random effects & 18.71 & & \\
\hline Intercept & & & \\
\hline
\end{tabular}

Model C: Wake after sleep onset

\begin{tabular}{lccc}
\hline Fixed effects & $B$ & $S E$ & $p$ \\
\hline Disease activity - inactive & -2.36 & 12.63 & $n s$ \\
Patient age & -.80 & 2.12 & $n s$ \\
Mean pain & -1.39 & 4.17 & $n s$ \\
Person-centered pain & -.29 & 1.44 & $n s$ \\
\hline Random effects & 579.25 & 190.92 & .002 \\
\hline Intercept & Model D: Total sleep time & \\
\hline & $B$ & $S E$ & $p$ \\
\hline Fixed effects & -19.16 & 25.61 & $n s$
\end{tabular}




\begin{tabular}{lccc} 
Patient age & -12.40 & 4.25 & .008 \\
Mean pain & 7.85 & 8.41 & $n s$ \\
Person-centered pain & 4.97 & 6.04 & $n s$ \\
\hline Random effects & & & .022 \\
\hline Intercept & 1799.75 & 785.13 & $n s$ \\
Person-centered pain & 6.17 & 208.59 & \\
\hline
\end{tabular}

Note: $n s=$ non-significant 
Table 10

Multilevel Model of Sleep Variables Predicting Abdominal Pain

\begin{tabular}{|c|c|c|c|}
\hline \multicolumn{4}{|c|}{ Model E: Next day pain } \\
\hline Fixed effects & $B$ & $S E$ & $p$ \\
\hline Disease activity - inactive & -.35 & .74 & $n s$ \\
\hline Patient age & .10 & .14 & $n s$ \\
\hline Mean sleep onset latency & -.04 & .13 & $n s$ \\
\hline Mean sleep efficiency & -.07 & .25 & $n s$ \\
\hline Mean wake after sleep onset & -.01 & .04 & $n s$ \\
\hline Mean total sleep time & .01 & .01 & $n s$ \\
\hline $\begin{array}{l}\text { Person-centered sleep onset } \\
\text { latency }\end{array}$ & $<-.01$ & .01 & $n s$ \\
\hline $\begin{array}{l}\text { Person-centered sleep } \\
\text { efficiency }\end{array}$ & $<-.01$ & .02 & $n s$ \\
\hline $\begin{array}{l}\text { Person-centered wake after } \\
\text { sleep onset }\end{array}$ & $<.01$ & $<.01$ & $n s$ \\
\hline $\begin{array}{l}\text { Person-centered total sleep } \\
\text { time }\end{array}$ & $<-.01$ & $<.01$ & $n s$ \\
\hline \multicolumn{4}{|l|}{ Random effects } \\
\hline Intercept & 1.70 & .59 & .004 \\
\hline $\begin{array}{l}\text { Person-centered sleep } \\
\text { efficiency }\end{array}$ & $<.01$ & .01 & $n s$ \\
\hline $\begin{array}{l}\text { Person-centered total sleep } \\
\text { time }\end{array}$ & $<.01$ & $<.01$ & $n s$ \\
\hline
\end{tabular}

Note: $n s=$ non-significant 
Table 11

Multilevel Models of Negative Affect Predicting Sleep Variables

Model F: Sleep onset latency

\begin{tabular}{|c|c|c|c|}
\hline Fixed effects & $B$ & $S E$ & $p$ \\
\hline Disease activity - inactive & -2.45 & 1.95 & $n s$ \\
\hline Patient age & -.18 & .32 & $n s$ \\
\hline Mean negative affect & -.21 & .19 & $n s$ \\
\hline $\begin{array}{l}\text { Person-centered negative } \\
\text { affect }\end{array}$ & .15 & .17 & $n s$ \\
\hline \multicolumn{4}{|l|}{ Random effects } \\
\hline Intercept & 1.36 & 4.43 & $n s$ \\
\hline \multicolumn{4}{|c|}{ Model G: Sleep efficiency } \\
\hline & $B$ & $S E$ & $p$ \\
\hline \multicolumn{4}{|l|}{ Fixed effects } \\
\hline Disease activity - inactive & -.60 & 2.31 & $n s$ \\
\hline Patient age & -.39 & .39 & $n s$ \\
\hline Mean negative affect & -.19 & .23 & $n s$ \\
\hline $\begin{array}{l}\text { Person-centered negative } \\
\text { affect }\end{array}$ & .01 & .08 & $n s$ \\
\hline \multicolumn{4}{|l|}{ Random effects } \\
\hline Intercept & 17.95 & 6.49 & .006 \\
\hline \multicolumn{4}{|c|}{ Model H: Wake after sleep onset } \\
\hline Fixed effects & $B$ & $S E$ & $p$ \\
\hline Disease activity - inactive & -.45 & 12.08 & $n s$ \\
\hline Patient age & -.55 & 2.05 & $n s$ \\
\hline Mean negative affect & 1.49 & 1.18 & $n s$ \\
\hline $\begin{array}{l}\text { Person-centered negative } \\
\text { affect }\end{array}$ & -.09 & .30 & $n s$ \\
\hline \multicolumn{4}{|l|}{ Random effects } \\
\hline Intercept & 535.86 & 177.16 & .002 \\
\hline
\end{tabular}




\begin{tabular}{lccc}
\hline \multicolumn{3}{c}{ Model I: Total sleep time } & \\
\hline Fixed effects & $B$ & $S E$ & $p$ \\
\hline Disease activity - inactive & -21.93 & 25.74 & $n s$ \\
Patient age & -11.74 & 4.32 & .013 \\
Mean negative affect & .68 & 2.52 & $n s$ \\
Person-centered negative & .14 & 1.24 & $n s$ \\
affect & & & \\
\hline Random effects & & & .020 \\
\hline Intercept & 1874.16 & 808.05 &
\end{tabular}

Note: $n s=$ non-significant 
Table 12

Multilevel Model of Sleep Variables Predicting Negative Affect

Model J: Next day negative affect

\begin{tabular}{lccc}
\hline Fixed effects & $B$ & $S E$ & $p$ \\
\hline Disease activity - inactive & -1.51 & 2.43 & $n s$ \\
Patient age & -.37 & .47 & $n s$ \\
Mean sleep onset latency & -.56 & .41 & $n s$ \\
Mean sleep efficiency & -.80 & .81 & $n s$ \\
Mean wake after sleep onset & -.08 & .13 & $n s$ \\
Mean total sleep time & .03 & .03 & $n s$ \\
Person-centered sleep onset & .03 & .03 & $n s$ \\
latency & .06 & .08 & $n s$ \\
Person-centered sleep & & \\
efficiency & $<.01$ & .02 & $n s$ \\
Person-centered wake after & & & $n s$ \\
sleep onset & $<-.01$ & $<.01$ & \\
Person-centered total sleep & & 6.49 & .006 \\
time & 17.84 & & \\
\hline Random effects & & & \\
\hline Intercept & & & \\
\hline Note: $n s=$ non & & & \\
\hline
\end{tabular}

Note: $n s=$ non-significant 
Table 13

Multilevel Models of Positive Affect Predicting Sleep Variables

\section{Model K: Sleep onset latency}

\begin{tabular}{lccc}
\hline Fixed effects & $B$ & $S E$ & $p$ \\
\hline Disease activity - inactive & -2.34 & 1.89 & $n s$ \\
Patient age & -.02 & .32 & $n s$ \\
Mean positive affect & -.08 & .06 & $n s$ \\
Person-centered positive & .03 & .14 & $n s$ \\
affect & & & \\
\hline Random effects & .72 & 4.13 & $n s$ \\
Intercept & .12 & .17 & $n s$ \\
Person-centered positive & & & \\
affect & & &
\end{tabular}

Model L: Sleep efficiency

$B \quad S E \quad p$

\begin{tabular}{lccc}
\hline Fixed effects & & \\
\hline Disease activity - inactive & -.44 & 2.34 & $n s$ \\
Patient age & -.34 & .42 & $n s$ \\
Mean positive affect & $<-.01$ & .08 & $n s$ \\
Person-centered positive & -.04 & .05 & \\
affect & & & \\
\hline Random effects & 18.42 & 6.66 & \\
\hline Intercept & Model M: Wake after sleep onset & $n$ \\
\hline & -1.15 & $S E$ & $n s$ \\
\hline Fixed effects & -1.31 & 12.40 & $n s$ \\
\hline Disease activity - inactive & -.19 & 2.21 & $n s$ \\
Patient age & .23 & .42 & $n s$ \\
Mean positive affect & & .20 & \\
Person-centered positive & & & \\
affect & & & \\
\hline Random effects & & & \\
\hline
\end{tabular}




\begin{tabular}{lccc}
\hline Intercept & 565.79 & 186.66 & .002 \\
\hline \multicolumn{1}{l}{ Model N: Total sleep time } & & \\
\hline Fixed effects & $B$ & $S E$ & $n s$ \\
\hline Disease activity - inactive & -22.27 & 25.82 & .015 \\
Patient age & -12.07 & 4.56 & $n s$ \\
Mean positive affect & -.06 & .86 & $n s$ \\
Person-centered positive & .54 & .83 & \\
affect & & & .020 \\
\hline Random effects & 1887.87 & 811.56 & \\
\hline Intercept & & & \\
\hline
\end{tabular}

Note: $n s=$ non-significant 
Table 14

Multilevel Model of Sleep Variables Predicting Positive Affect

\section{Model O: Next day positive affect}

\begin{tabular}{|c|c|c|c|}
\hline Fixed effects & $B$ & $S E$ & $p$ \\
\hline Disease activity - inactive & 3.77 & 7.60 & $n s$ \\
\hline Patient age & -1.81 & 1.48 & $n s$ \\
\hline Mean sleep onset latency & .87 & 1.30 & $n s$ \\
\hline Mean sleep efficiency & -.18 & 2.54 & $n s$ \\
\hline Mean wake after sleep onset & -.09 & .41 & $n s$ \\
\hline Mean total sleep time & $<.01$ & .09 & $n s$ \\
\hline $\begin{array}{l}\text { Person-centered sleep onset } \\
\text { latency }\end{array}$ & -.06 & .05 & $n s$ \\
\hline $\begin{array}{l}\text { Person-centered sleep } \\
\text { efficiency }\end{array}$ & -.04 & .14 & $n s$ \\
\hline $\begin{array}{l}\text { Person-centered wake after } \\
\text { sleep onset }\end{array}$ & .02 & .03 & $n s$ \\
\hline $\begin{array}{l}\text { Person-centered total sleep } \\
\text { time }\end{array}$ & $<-.01$ & $<.01$ & $n s$ \\
\hline \multicolumn{4}{|l|}{ Random effects } \\
\hline Intercept & 186.36 & 63.46 & .003 \\
\hline $\begin{array}{l}\text { Person-centered wake after } \\
\text { sleep onset }\end{array}$ & $<.01$ & $<.01$ & $n s$ \\
\hline $\begin{array}{l}\text { Person-centered total sleep } \\
\text { time }\end{array}$ & $<.01$ & $<.01$ & $n s$ \\
\hline
\end{tabular}

Note: $n s=$ non-significant 